NBER WORKING PAPER SERIES

\title{
PATENT LICENSING AND THE RESEARCH UNIVERSITY
}

\author{
Richard Jensen \\ Marie Thursby \\ Working Paper 10758 \\ http://www.nber.org/papers/w10758 \\ NATIONAL BUREAU OF ECONOMIC RESEARCH \\ 1050 Massachusetts Avenue \\ Cambridge, MA 02138 \\ September 2004
}

We thank thank Paul David, Irwin Feller, Jerry Green, Josh Lerner, Richard Nelson, Paula Stephan, Tom Gresik, and seminar participants at the 2003 American Economic Assocation Meetings, the May 2003 NBER Higher Education Program Meeting, the California Institute of Technology, CORE, the Midwest Economic Theory Meetings at the University of Wisconsin, the Conference on Innovation and Intellectual Property at the University of Brussels, and the EARIE meetings at the University of Juan Carlos III in Madrid. Thursby thanks the Alan and Mildred Peterson Foundation and the National Science Foundation (SES-0094573) for financial support. This research was supported by grants RO1-HS/AG09630 and PO1-HS10770 from the Agency for Healthcare Research and Quality The views expressed herein are those of the author(s) and not necessarily those of the National Bureau of Economic Research.

(C2004 by Richard Jensen and Marie Thursby. All rights reserved. Short sections of text, not to exceed two paragraphs, may be quoted without explicit permission provided that full credit, including $\odot$ notice, is given to the source. 
Patent Licensing and the Research University

Richard Jensen and Marie Thursby

NBER Working Paper No. 10758

September 2004

JEL No. I2, L3, O32

\begin{abstract}
$\underline{\text { ABSTRACT }}$
We construct a dynamic model of university research that allows us to examine recent concerns that financial incentives associated with university patent licensing are detrimental to the traditional mission of US research universities. We assume a principal-agent framework in which the university administration is the principal and a faculty researcher is the agent. Whether or not the researcher remains in the university, and if so her choice of the amount of time to spend on basic and applied research, is complicated by the fact that she earns license income and prestige both inside and outside the university. Thus in contrast to usual principal agent models the participation constraint is endogenous. This, plus the fact that current research affects future knowledge stocks, allows us to show that it is far from obvious that licensing will damage basic research and education.

Richard A. Jensen

Department of Economics and Econometrics

434 Flanner

University of Notre Dame

Notre Dame, IN 46556

rjensen@nd.edu

Marie C. Thursby

College of Management

800 W. Peachtree Street NW

Georgia Institute of Technology

Atlanta, GA 30332

and NBER

marie.thursby@mgt.gatech.edu
\end{abstract}




\title{
Patent Licensing and the Research University
}

\author{
Richard Jensen* \\ The University of Notre Dame \\ Marie Thursby \\ Georgia Institute of Technology and NBER
}

September 9, 2004

\begin{abstract}
We construct a dynamic model of university research that allows us to examine recent concerns that financial incentives associated with university patent licensing are detrimental to the traditional mission of US research universities. We assume a principal-agent framework in which the university administration is the principal and a faculty researcher is the agent. Whether or not the researcher remains in the university, and if so her choice of the amount of time to spend on basic and applied research, is complicated by the fact that she earns license income and prestige both inside and outside the university. Thus in contrast to usual principal agent models the participation constraint is endogenous. This, plus the fact that current research affects future knowledge stocks, allows us to show that it is far from obvious that licensing will damage basic research and education.
\end{abstract}

\section{Introduction}

A sequence of related policy changes in the 1980's increased both the ability and incentive for U.S. universities to patent and license the results of faculty

\footnotetext{
${ }^{*}$ We thank thank Paul David, Irwin Feller, Jerry Green, Josh Lerner, Richard Nelson, Paula Stephan, Tom Gresik, and seminar participants at the 2003 American Economic Assocation Meetings, the May 2003 NBER Higher Education Program Meeting, the California Institute of Technology, CORE, the Midwest Economic Theory Meetings at the University of Wisconsin, the Conference on Innovation and Intellectual Property at the University of Brussels, and the EARIE meetings at the University of Juan Carlos III in Madrid. Thursby thanks the Alan and Mildred Peterson Foundation and the National Science Foundation (SES-0094573) for financial support.
} 
research. The Bayh-Dole Act of 1980 gave universities the right to own, patent, and license results of federally-funded research, and the Supreme Court approved patentability of genetically engineered bacteria and software, thereby expanding patentability of inventions in biological and computer sciences. ${ }^{1}$ Since then there has been a dramatic increase in patent activity in U.S. universities. For example, the 86 universities responding to the Association of University Technology Managers (AUTM) Survey in 1991 and 1998 reported an increase in patent applications of 176 percent and licenses executed of 131 percent. While university administrators cite such figures as evidence of the increasing role of universities in economic development, others see the dramatic increase in patent licensing as problematic, potentially compromising the traditional role of universities in research and education. $^{2}$

Two issues of concern are the nature of faculty research and the way results are disseminated. The conventional wisdom is that faculty have both a comparative advantage and a taste for basic research. Publication of this research creates a nonexcludable public good which serves as a basis for further research in industry as well as academia. Thus to the extent that faculty receive license income from patentable research, the concern is that they will be diverted from basic research and/or limit the dissemination of their work, putting both current and future innovation at risk (Griliches 1988, Osano 1992).

Those concerned about the impact on education raise several issues. While they recognize that faculty involvement in patent licensing has the potential to improve curricula, they express concern that faculty may spend less time in education as they pursue entrepreneurial activities associated with licensing. Critics, in fact, worry that university administrators may encourage such activity in the interest of capturing license income. ${ }^{3}$ The

\footnotetext{
${ }^{1}$ Other patent reforms in the 1980s, such as the creation of the Federal Circuit Court and the lengthening of patent life for pharmaceuticals, also strengthened patent protection for businesses as well as universities. Here we focus on those changes that were particularly relevant for university inventions. See Gallini (2002) for a discussion of the implications of these reforms for businesses.

${ }^{2}$ These issues are sufficiently controversial to be the subject of a recent cover story of Atlantic Monthly titled "The Kept University" (Press and Washburn 2000). Moreover, Congress, the Science, Technology and Economics Policy (STEP) board of the National Research Council, and the President's Commission on Science and Technology have all undertaken review of university patenting.in the context of Bayh-Dole.

${ }^{3}$ Cash constrained universities in the United Kingdom explicitly encourage faculty to engage in income generating activities, such as applied research and/or consultancy, and tax the resulting income to increase university resources (see Beath et al. 2003).
} 
most serious concern, however, is that the patent process may prevent or delay the use of research results in the lab or classroom, diminishing the quality of education (Stephan 2001, and Stephan and Levin 1996).

Amid the rhetoric there is little formal analysis of these issues. While recent empirical research provides some evidence that applied research has increased (Cohen et al. 1994, Lach and Schankerman 2002, Morgan et al. 1997, Rahm 1994), others show little change over the last two decades in the ratio of applied to basic research (Thursby and Thursby 2004). And although there is some research on the effects of financial incentives on the allocation of time between applied and basic research (Beath et al. 2003 and Jensen and Thursby 2001), there is none on the corresponding effects on the future stocks of scientific and patentable knowledge and on the quality of education.

We therefore construct a dynamic model of a research university that allows us to examine these issues. The university produces scientific knowledge, patentable knowledge, and education of variable quality using a researcher, a faculty member whose current research choices affect educational quality and future knowledge stocks. Our intent is to analyze the effects of these recent policy changes on the allocation of time between basic and applied research, and thus on the stocks of knowledge and the quality of education. The stock of scientific knowledge earns prestige for the researcher and the administration, while the stock of patentable knowledge earns license income as well as prestige. We assume a principal-agent relationship in which the university is the principal. The administration chooses her salary and teaching load, taking into account her productivity in research and education and the resulting income from licensing and tuition. If the researcher works for the university, she allocates her time between teaching and two types of research, basic and applied. Prestige and income provide utility for both the researcher and administration. The researcher, however, also receives utility simply from the time spent on each type of research. Administration income also depends on the quality of education, which in turn depends on the research output that is available for use in the classroom and the time the faculty spends on education. While the stock of scientific knowledge is freely available for use in education, we assume only a portion of the stock of patentable knowledge can be used prior to actual patenting. This allows us to examine the concern that patenting compromises the quality of education by limiting the dissemination of knowledge. It should be noted that because the researcher retains her share of license income and the knowledge stocks if she leaves the university, her reservation utility is not exogenously fixed as in usual principal-agent models, but instead is a 
function of both her share and the knowledge stocks.

Whether the researcher specializes in basic or applied research, or spends some time on each, in any period depends on the marginal rate of substitution of applied for basic research. In a static problem, this merely takes into account the utility associated with each type of research. However, in a dynamic environment, this marginal rate of substitution also incorporates the productivity of this research in adding to future knowledge stocks, and so to income and prestige. Although it seems likely that an increase in income associated with patent licensing would induce her to reallocate time to applied research, this is not necessary. This reallocation should increase the future stock of patentable knowledge she produces, but it should also reduce the future stock of scientific knowledge and its associated prestige, and it could also reduce her utility from research per se. In fact, it is not clear that this reallocation would increase the stock of patentable knowledge for faculty whose basic research yields both patentable and scientific knowledge (i.e., those whose work falls in the much publicized Pasteur's Quadrant (Stokes 1997)). In an interior solution for any period, an increase in her teaching load decreases the time she devotes to both basic and applied research. A change in her salary, her share of license income, and either current stock of knowledge results in a reallocation of time to applied research if and only if this change increases the marginal rate of substitution of applied for basic research.

In each period, the equilibrium salary and teaching load are set so that her participation constraint binds and the administration's willingness to pay her to teach an additional hour equals her marginal rate of substitution between research and income. Her participation constraint is positively sloped, so she must be paid a higher salary to carry a greater teaching load. Although we focus on interior solutions, one corner solution is noteworthy. It may be optimal for the administration to allow star scientists to specialize completely in research. In this case, offering them a higher salary to induce them to teach more reduces their production of both knowledge stocks and thus may lower the quality of education and reduce tuition revenue.

Comparative statics reveal that the equilibrium teaching load and salary chosen by the administration in any period may or may not change in response to a change in the researcher's share of license income. If preferences are homothetic, we show that the researcher's share of license income has no effect on her teaching load, and thus no effect on her allocation of time between basic and applied research. In general, if a change in her share affects her utility within the university the same as her reservation utility, which is likely as she can continue to earn license income after she exits, then there 
is no change in her participation constraint. In this case, the change in her share either has no effect on the optimal teaching load or her salary (as in the case of homothetic preferences), or causes them to move in the same direction. Note, however, that a change in the teaching load does not affect the researcher's allocation of time between basic and applied research unless it changes the marginal rate of substitution between the two types of research.

We also examine the effect of changes in the researcher's current stocks of scientific and patentable knowledge on the equilibrium teaching load and salary. If the prestige associated with scientific knowledge is greater within the university, then an increase in its current stock typically decreases the salary and increases the teaching load, but in general cannot both increase the salary and decrease the teaching load. If the prestige associated with patentable knowledge is greater outside the university, then an increase in its current stock typically increases the salary and decreases the teaching load, but in general cannot both decrease the salary and increase the teaching load. Because the researcher's utility does not depend on the portion of patentable knowledge that can be disseminated in education, a change in this portion has no effect on her participation constraint. Thus a decrease in this portion either has no effect on the teaching load or her salary (as for homothetic preferences), or causes them to move in the same direction.

We assume the quality of education is increasing in the teaching load and the knowledge stocks used in education. The effects of these policy changes on equilibrium educational quality are not obvious. For example, if an increase in the share has no effect on the current teaching load, then it has no effect on the current or future quality of education. However, if an increase in the share decreases the current teaching load, then the current quality of education declines. The reduction in the current teaching load increases current research and therefore the future knowledge stocks. The effects of these changes on the future choices of both the researcher and administration, and therefore the future quality of education, are ambiguous. Analogously, a decrease in the portion of patentable knowledge that can be disseminated generally has ambiguous effects.

Thus, to the extent that the court's extension of patent protection to research in biological and computer sciences increased opportunities for faculty outside the university, it could have led to increased university salaries and lower teaching loads. Bayh-Dole would have reinforced this effect as administrators would be willing to pay more for less time spent in education because they could substitute license income for tuition. It is nonetheless important to observe that this need not have led to a decrease in the quality 
of education. The increase in patentable knowledge would tend to increase the quality of education, ceteris paribus. There is evidence, however, of communication restrictions associated with commercialization which could have resulted in a decrease in the amount of this knowledge actually used in education. Blumenthal et al. (1997) and Louis et al. (2001) find that faculty in the life sciences who are involved with commercialization are more likely to withhold information from colleagues than other faculty. In Thursby and Thursby's (2002) survey of businesses who license from universities, 50 percent of the respondents reported that their contracts specified delays of publication and rights to delete information. To the extent that this is the case, our results show that the critics have legitimate concerns because the university administration's incentive to reduce teaching loads would have to be offset by increases in the amount of patentable knowledge used in education in order to avoid a decrease in the quality of education.

These results contribute to the growing literature on university patenting, which with few exceptions has abstracted from the implications for basic research and education. ${ }^{4}$ Much of the literature focuses on the role of patent citations and patent licensing in the transfer of research to industry (see, for example, Henderson et al. 1998, Jaffe et al. 1993, Jensen and Thursby 2001, Mowery et al. $2001 \mathrm{a}, \mathrm{b}$ ). Thursby and Thursby (2002) provide evidence to support the view that entrepreneurial university administrations and faculty research orientation have both been factors in increased university patenting, but they do not address issues related to education. With the exception of recent work by Beath et al. (2003), studies of the tension between basic and applied research have focused on the behavior of profit-maximizing firms (Osano 1992, Cockburn, Henderson, and Stern 1999, and Stern 2004). Beath et al. (2003) show that universities may want to allow faculty to conduct applied research on a consulting basis in order to ease the university's budget constraint, however, they do not examine the implications of such work for the quality of university education.

Our results also contribute to the literature on teaching, research, and educational quality. Recent work by del Ray (2001) examines how different

\footnotetext{
${ }^{4}$ The related literature on university-industry collaboration has examined the effects on research, but not education. Cohen et.al (1998) provide a useful review. Cohen et.al's (1994) survey of university-industry research centers (UIRCs) provides evidence of the countervailing effects of industry collaboration on faculty productivity, with so-called commercial outputs of research increasing and publications decreasing (except in biotechnology). On the other hand, Mansfield's (1995) study of 321 academic researchers shows a complementarity between consulting and basic research. Similarly, Zucker et. al.(1994, 1998) found that the most productive scientists in biotechnology tend to capitalize on commercial applications of their basic research.
} 
schemes for financing undergraduate education affect the quality of education. In this, as well as earlier work (see Barooah 1991), the quality of education is determined by the quality of students admitted and the resources devoted to teaching. By contrast, we model quality as a function of the knowledge that can be shared in the classroom as well as the amount of time devoted to teaching.

\section{A Model of The Research University}

We consider a research university that produces three outputs in each period $t$ : scientific knowledge $k_{t}$; patentable knowledge $p_{t}$; and education of quality $q_{t}$. Production of each output requires use of a university researcher, $F$, who is a member of the faculty. The researcher's career begins at $t=1$ and ends at $t=2$. In each period, she can work for the university or exit to her next best alternative. That is, we assume a principal-agent relationship with the university as the principal and the researcher as the agent. If she works for the university, she allocates her time between teaching and the two types of research. We normalize time available in each period $t$ so that $a_{t}$ is the fraction of time devoted to applied research in the university, $b_{t}$ is the fraction of time devoted to basic research, and $e_{t}=1-a_{t}-b_{t}$ is the fraction of time spent in teaching at $t$. As is standard in science and engineering departments, the teaching load is defined by total student contact hours, which includes activities such as advising dissertations or lab research as well as classroom instruction. If she exits, then she receives her reservation utility. Unlike usual principal-agent models, however, her reservation utility is not an exogenously fixed value, because there are alternatives in which she can continue her basic and/or applied research, such as move to another university or a firm in the private sector, or establish a start-up firm. Her reservation utility must be a function of the knowledge she takes with her.

\subsection{Preferences}

Researchers have preferences that depend on both pecuniary and nonpecuniary sources: income, research effort itself, and the prestige resulting from successful research. In particular, we assume the researcher's utility in period $t$ is given by $U_{F}\left(a_{t}, b_{t} ; Y_{F t}, p_{t}, k_{t}\right)$, where $Y_{F t}$ is her income and $p_{t}$ and $k_{t}$ are the knowledge stocks at $t$. The assumption that utility is a function of time spent in research is consistent with the notion that researchers who do basic research may have a taste for it (see Stern (2004)). We take this idea one step further by assuming that some researchers may also have a taste for 
applied research. That is, we focus on faculty who get utility from simply working on research problems, and who view research as a "...puzzle-solving operation in which the solution of the puzzle is its own reward" (Hagstrom (1965, p. 16); see also Kuhn (1970)). There is substantial evidence that such researchers also get utility from the prestige associated with the successes of their research (see Stephan (1996) for a survey). We use the stocks of knowledge as measures of this prestige, so that past success in either basic or applied research generates additional current and future utility, independently of whether it generates additional income. By not including time spent teaching in the utility function, we merely limit our focus to faculty for whom research provides greater utility than teaching. We make the standard assumptions that $U_{F}\left(a_{t}, b_{t} ; Y_{F t}, p_{t}, k_{t}\right)$ has positive marginal utilities and is strictly quasi-concave in $\left(a_{t}, b_{t}\right)$. It is convenient to characterize many of the results that follow in terms of marginal rates of substitution. For any $x, y=a_{t}, b_{t}, Y_{F t}, p_{t}, k_{t}$, define $m_{x y}\left(a_{t}, b_{t} ; Y_{F t}, p_{t}, k_{t}\right)=\frac{\frac{\partial U_{F}\left(a_{t}, b_{t} ; Y_{F t}, p_{t}, k_{t}\right)}{\partial x}}{\frac{\partial U_{F}\left(a_{t}, b_{t} ; Y_{F t}, p_{t}, k_{t}\right)}{\partial y}}$ as the marginal rate of substitution of $x$ for $y$. Normally one would assume, as we shall, that the marginal rate of substitution of applied for basic research, $m_{a b}=\frac{\frac{\partial U_{F}}{\partial a_{t}}}{\frac{\partial U_{F}}{\partial b_{t}}}$, is decreasing in $a_{t}$ and increasing in $b_{t}$.

As a faculty member, the researcher earns income from her university salary and her share of the university's license income from its patentable knowledge. License income in each period $t$ depends on the current stock of patentable knowledge, $L_{t}=L\left(p_{t}\right)$. We denote the salary in period $t$ by $s_{t}$, and the share of license income for the researcher by $\phi$, so current income for a faculty researcher at $t$ is

$$
Y_{F t}=Y_{F}\left(s_{t}, \phi, p_{t}\right)=s_{t}+\phi L\left(p_{t}\right)
$$

Naturally we assume that $L_{t}(0)=0$. Notice that, because research does not increase the stock of knowledge until the next period, current effort effects future income and prestige, but not current income.

The administration maximizes his utility subject to the researcher's participation constraint. His utility at $t$ is given by $U_{A}\left(Y_{A t} ; p_{t}, k_{t}\right)$, where $Y_{A t}$ is the university's net income. Again, we assume that $U_{A}\left(Y_{A t} ; p_{t}, k_{t}\right)$ has nonnegative marginal utilities and is strictly concave in $Y_{A t}$. In each period the university earns enrollment income, $T$, which depends on the quality of education, $q_{t}$. For simplicity we assume the faculty researcher or her replacement is the only variable input, so the university's net income is

$$
Y_{A t}=Y_{A}\left(s_{t}, \phi, p_{t}, q_{t}\right)=T\left(q_{t}\right)+(1-\phi) L\left(p_{t}\right)-s_{t} .
$$


If the faculty researcher exits, we assume the university can hire a replacement who can take full advantage of the stocks of scientific and patentable knowledge. In each period, the administration chooses the time the researcher spends in education (the teaching load), $e_{t}$, and her salary, $s_{t}$.

\subsection{Production}

In period $t$, the researcher's stock of patentable knowledge is $p_{t}$, and the stock of scientific knowledge is $k_{t}$. Her allocation of time between applied and basic research in period $t$ determines the increments to these stocks which are realized in period $t+1$. The production functions for knowledge are therefore given by $p_{t+1}=P\left(a_{t}, b_{t} ; p_{t}, k_{t}\right)$ and $k_{t+1}=K\left(a_{t}, b_{t} ; p_{t}, k_{t}\right)$, which are assumed to be increasing and jointly concave in their arguments. The stocks of knowledge are given by the initial values $\left(p_{1}, k_{1}\right)$, and then $p_{t+1}=p_{t}+\left(P\left(a_{t}, b_{t} ; p_{t}, k_{t}\right)-p_{t}\right)$ and $k_{t+1}=k_{t}+\left(K\left(a_{t}, b_{t} ; p_{t}, k_{t}\right)-k_{t}\right)$ in subsequent periods. We therefore allow for research in "Pasteur's Quadrant," where a researcher's basic research produces both patentable and scientific knowledge, as well as the type of research characterized by Mansfield in which applied research has a positive impact on the researcher's basic research agenda (Mansfield 1995 and Stokes 1997).

The production of educational quality depends on the time the researcher spends in education as well as the stocks of knowledge that can be freely disseminated. While the increments to scientific knowledge can be disseminated freely as soon as they are realized, patentable knowledge cannot. One provision of the Bayh-Dole Act is that in order to claim title to federally funded inventions, universities must file patent applications. Thus patentable knowledge may not be used in education until the patent application is filed or perhaps even granted. To capture this, as well as the tendency of companies to restrict information associated the technologies they license, we assume the patentable knowledge that can be disseminated in each period is $\theta p_{t}$. We then assume that the production of educational quality is given by $q_{t}=Q\left(e_{t} ; \theta p_{t}, k_{t}\right)$, which we assume is increasing and jointly concave in its arguments.

This is one way to capture the controversy surrounding Bayh-Dole and related changes in patent policy regarding educational quality. There would be no incentive to delay dissemination of patentable knowledge if the university did not own the patent rights, so $\theta=1$ and educational quality would be $q_{t}=Q\left(e_{t} ; p_{t}, k_{t}\right)$. Moreover, critics have argued that this legislation can lead to a substitution of applied research for education. This approach also allows us to highlight the fact that there is a trade-off in educational qual- 
ity between reduced time in education and increased knowledge that results from increased research.

In the sequel we consider a two-period problem so that we can analyze, compare, and contrast the equilibrium outcomes in both static and dynamic environments. An extension to more periods would add nothing new to this analysis. The proofs of following theorems that are not included in the text are given in the Appendix.

\section{The Period-Two, Static Equilibrium}

As usual, we solve for the equilibria by backward induction, starting in the final period. In this section, all values therefore refer to those in period two.

\subsection{The Faculty Researcher's Problem}

In the second period, there is no future, so the researcher's problem if she remains with the university is to choose effort to maximize current utility subject to the time constraint. The time the researcher must spend in education and the salary, as well as the knowledge stocks, and hence her income, are given when she makes the choice of effort. Substituting the time constraint, her problem can be restated as

$$
\max _{b_{2} \in\left[0,1-e_{2}\right]} U_{F}\left(1-e_{2}-b_{2}, b_{2} ; Y_{F 2}, p_{2}, k_{2}\right) .
$$

Keeping in mind that the "relative price" of each type of research is one, the next result follows immediately.

Theorem 1 Let $a_{2}^{*}\left(e_{2}, s_{2} ; \phi, p_{2}, k_{2}\right)$ and $b_{2}^{*}\left(e_{2}, s_{2} ; \phi, p_{2}, k_{2}\right)$ solve the researcher's optimization problem in (3). Then the researcher specializes in basic research, $a_{2}^{*}=0$ and $b_{2}^{*}=1-e_{2}$, if

$$
m_{a b}\left(0,1-e_{2} ; Y_{F 2}, p_{2}, k_{2}\right) \leq 1,
$$

specializes in applied research, $a_{2}^{*}=1-e_{2}$ and $b_{2}^{*}=0$, if

$$
m_{a b}\left(1-e_{2}, 0 ; Y_{F 2}, p_{2}, k_{2}\right) \geq 1,
$$

and devotes effort to each type of research, $a_{2}^{*}>0, b_{2}^{*}>0$, and $a_{2}^{*}+b_{2}^{*}=$ $1-e_{2}$, if (4) and (5) do not hold, in which case

$$
m_{a b}\left(a_{2}^{*}, b_{2}^{*} ; Y_{F 2}, p_{2}, k_{2}\right)=1
$$


If the marginal rate of substitution of applied for basic research is too low (less than one) when she specializes in basic research, then that specialization is optimal. If this marginal rate of substitution of applied for basic research is too high (greater than one) when she specializes in applied research, then that specialization is optimal. Otherwise, the remaining time available after education is allocated between effort in applied and basic research so that the marginal rate of substitution between them equals one, as in (6). In this case, the comparative statics have the expected properties.

Theorem 2 In an interior solution to (3), an increase in time spent in education implies decreases in effort in both basic and applied research. A change in the salary, the share of license income, and either stock of knowledge implies an increased allocation of effort to applied research if and only if that change increases the marginal rate of substitution of applied for basic research.

The researcher's indirect utility function is then

$$
V_{F 2}\left(e_{2}, s_{2}, \phi, p_{2}, k_{2}\right)=U_{F}\left(a_{2}^{*}, b_{2}^{*} ; s_{2}, \phi, p_{2}, k_{2}\right) .
$$

For any given utility, $v$, the equation $V_{F 2}\left(e_{2}, s_{2}, \phi, p_{2}, k_{2}\right)=v$ implicitly defines an indifference curve in education-salary space for the inventor, $I_{F 2}\left(e_{2}, \phi, p_{2}, k_{2}, v\right)$. The properties of this indirect utility function and its indifference curve map are crucial to understanding the administration's choices.

Theorem 3 The researcher's indirect utility function is increasing in her salary, her share of license income, and both knowledge stocks, but decreasing in her time spent in education: $\frac{\partial V_{F 2}}{\partial s_{2}}>0, \frac{\partial V_{F 2}}{\partial \phi}>0, \frac{\partial V_{F 2}}{\partial k_{2}}>0, \frac{\partial V_{F 2}}{\partial p_{2}}>0$, and $\frac{\partial V_{F 2}}{\partial e_{2}}<0$. Thus, a researcher's typical indifference curve in $\left(e_{2}, s_{2}\right)$ space is positively sloped, and decreasing in her share of license income and both knowledge stocks.

Each indifference curve is positively sloped because she must be paid a higher salary to accept a heavier teaching load. It is worth noting that this slope is

$$
\frac{\partial I_{F 2}\left(e_{2}, \phi, p_{2}, k_{2}, v\right)}{\partial e_{2}}=m_{a Y_{F}}\left(a_{2}^{*}, b_{2}^{*} ; Y_{F 2}, p_{2}, k_{2}\right)=m_{b Y_{F}}\left(a_{2}^{*}, b_{2}^{*} ; Y_{F 2}, p_{2}, k_{2}\right),
$$

the marginal rate of substitution between time in either type of research and income. An increase in her share of license income or either knowledge 
stock shifts each indifference curve down since the utility associated with any point in $\left(e_{2}, s_{2}\right)$ space increases.

She also has the option of exiting the university for other opportunities. If she does, then we assume her reservation utility is $\bar{U}_{F 2}\left(\phi, p_{2}, k_{2}\right)$. As noted above, unlike usual principal-agent models, her reservation utility cannot be an exogenously determined constant. Her best external option must depend on the stock of patentable knowledge and her share of the revenue from it, because she does not forfeit her license income when she departs. It also depends on the scientific knowledge stock because her external options may depend upon the prestige associated with her stock of scientific knowledge, which she is free to use in any alternative employment opportunity. For any $\left(\phi, p_{2}, k_{2}\right)$ she remains in the university only if her participation constraint,

$$
V_{F 2}\left(e_{2}, s_{2}, \phi, p_{2}, k_{2}\right) \geq \bar{U}_{F 2}\left(\phi, p_{2}, k_{2}\right),
$$

is satisfied.

Theorem 4 Assume there exist $s_{L 2}$ and $s_{H 2}$ such that $s_{H 2}>s_{L 2}>0$,

$$
V_{F 2}\left(0, s_{L 2}, \phi, p_{2}, k_{2}\right)=\bar{U}_{F 2}\left(\phi, p_{2}, k_{2}\right),
$$

and

$$
V_{F 2}\left(1, s_{H 2}, \phi, p_{2}, k_{2}\right)=\bar{U}_{F 2}\left(\phi, p_{2}, k_{2}\right) .
$$

Then $V_{F 2}\left(e_{2}, s_{2}, \phi, p_{2}, k_{2}\right)=\bar{U}_{F 2}\left(\phi, p_{2}, k_{2}\right)$ defines a function $S_{2}\left(e_{2}, \phi, p_{2}, k_{2}\right)$, where $S_{2}$ maps $[0,1]$ onto $\left[s_{L 2}, s_{H 2}\right]$, such that the participation constraint binds for all $\left(e_{2}, s_{2}\right)=\left(e_{2}, S_{2}\left(e_{2}, \phi, p_{2}, k_{2}\right)\right)$ and:

(1) $S_{2}$ is increasing in the time spent in education, $\frac{\partial S_{2}}{\partial e_{2}}>0$.

(2) $S_{2}$ is increasing (decreasing, constant) in the inventor's share or either knowledge stock if and only if the effect of a change in that parameter on her reservation utility is greater than (less than, equal to) that on her utility within the university, or $\frac{\partial S_{2}}{\partial x}>(<,=) 0$ if and only if $\frac{\partial \bar{U}_{F 2}}{\partial x}>(<,=) \frac{\partial V_{F 2}}{\partial x}$ for $x=\phi, p_{2}, k_{2}$.

That is, $S_{2}\left(e_{2}, \phi, p_{2}, k_{2}\right)=I_{F 2}\left(e_{2}, \phi, p_{2}, k_{2}, \bar{U}_{F 2}\left(\phi, p_{2}, k_{2}\right)\right)$ is the indifference curve where the participation constraint (9) binds. The conditions in (10) and (11), together with the results of Theorem 3, state that she will not work for the university, even if she does not have to teach, unless she is paid a salary of at least $s_{L 2}$. Similarly, she must be paid a greater salary of at least $s_{\mathrm{H} 2}$ if the university wants her to teach full time. This indifference curve must be positively sloped, of course, $\frac{\partial S_{2}}{\partial e_{2}}>0$. An example 
is depicted in Figure 1, where her utility increases to the northwest. For any point on $S_{2}\left(e_{2}, \phi, p_{2}, k_{2}\right)$, the participation constraint binds and she is indifferent between remaining in the university and exiting. For any point above $S_{2}\left(e_{2}, \phi, p_{2}, k_{2}\right)$, she remains in the university because she earns rents, $V_{F 2}\left(e_{2}, s_{2}, \phi, p_{2}, k_{2}\right)=\bar{U}_{F 2}\left(\phi, p_{2}, k_{2}\right)$, but for any point below she exits because $V_{F 2}\left(e_{2}, s_{2}, \phi, S_{2}\left(e_{2}, \phi, p_{2}, k_{2}\right)\right)<\bar{U}_{F 2}\left(\phi, p_{2}, k_{2}\right)$.

A change in any of the parameters $\phi, k_{2}$, or $p_{2}$ has an uncertain effect on the location of $S_{2}\left(e_{2}, \phi, p_{2}, k_{2}\right)$ because an increase in any of these parameters not only increases the utility she associates with any $\left(e_{2}, s_{2}\right)$ if she remains in the university, but also increases her reservation utility if she exits. That is, the sign of $\frac{\partial S_{2}}{\partial x}$ is given by the sign of $\frac{\partial \bar{U}_{F 2}}{\partial x}-\frac{\partial V_{F 2}}{\partial x}$ for $x=\phi, k_{2}, p_{2}$. If the effect on her reservation utility is greater, then $S_{2}\left(e_{2}, \phi, p_{2}, k_{2}\right)$ shifts up in $\left(e_{2}, s_{2}\right)$ space. Conversely, if the effect on her utility within the university is greater (as we might expect, for example, if the knowledge is "firm-specific"), then $S_{2}\left(e_{2}, \phi, p_{2}, k_{2}\right)$ shifts down in $\left(e_{2}, s_{2}\right)$ space.

\subsection{The Administration's Problem}

Substituting the production relation for educational quality $q_{2}=Q\left(e_{2} ; \theta p_{2}, k_{2}\right)$ into university net income gives $Y_{A 2}=T\left(Q\left(e_{2} ; \theta p_{2}, k_{2}\right)\right)+(1-\phi) L\left(p_{t}\right)-s_{t}$, and so the administration's utility can be expressed as a function the researcher's time in education and her salary, as well as the parameters of the model,

$$
\left.V_{A 2}\left(e_{2}, s_{2} ; \phi, \theta, p_{2}, k_{2}\right)\right)=U_{A}\left(Y_{A 2}\left(s_{2}, \phi, p_{2}, q_{2}\right), p_{2}, k_{2}\right) .
$$

For a given level of utility, $v$, the equation $V_{A 2}\left(e_{2}, s_{2} ; \phi, \theta, p_{2}, k_{2}\right)=v$ implicitly defines an indifference curve in education-salary space for the administration, $I_{A 2}\left(e_{2}, \phi, \theta, p_{2}, k_{2}, v\right)$.

Theorem 5 The administration's utility function is increasing in the time spent by the researcher in education and both knowledge stocks, but decreasing in her salary and her share of license income: $\frac{\partial V_{A 2}}{\partial e_{2}}>0, \frac{\partial V_{A 2}}{\partial k_{2}}>0$, $\frac{\partial V_{A 2}}{\partial p_{2}}>0$, and $\frac{\partial V_{A 2}}{\partial \theta}>0$, but $\frac{\partial V_{A 2}}{\partial s_{2}}<0$ and $\frac{\partial V_{A 2}}{\partial \phi}<0$. Thus, an administration's typical indifference curve in $\left(e_{2}, s_{2}\right)$ space is positively sloped, increasing in both knowledge stocks and the portion of patentable knowledge disseminated, but decreasing in the researcher's share of license income.

The administration's indifference curve in $\left(e_{2}, s_{2}\right)$ space is also positively sloped, so it allows the researcher to spend less time in education only if it 
can pay her a lower salary. The slope of this indifference curve is

$$
\frac{\partial I_{A 2}\left(e_{2}, \phi, \theta, p_{2}, k_{2}, v\right)}{\partial e_{2}}=T^{\prime}\left(q_{2}\right) \frac{\partial q_{2}\left(e_{2} ; \theta p_{2}, k_{2}\right)}{\partial e_{2}} .
$$

A change in the time she spends in education changes the quality of education and thus tuition revenue. That is, $T^{\prime}\left(q_{2}\right) \frac{\partial q_{2}\left(e_{2} ; \theta, p_{2}, k_{2}\right)}{\partial e_{2}}$ is her marginal effect tuition income through educational quality, or her marginal revenue product in education. Thus, given a decrease in her teaching load, her salary must be decreased by an amount equal to the resulting tuition decrease to maintain the administration at the same level of income and utility. An increase in either knowledge stock or the portion of patentable stock disseminated shifts each of its indifference curves up, since the utility associated with any point in $\left(e_{2}, s_{2}\right)$ space increases, so it will pay more for her to carry the same teaching load. Conversely, an increase in her share (which is a decrease in its share) shifts each of its indifference curves down, so it will pay less for her to carry the same teaching load.

Because its utility is increasing in the time in education and decreasing in the salary, it follows from the preceding theorem that her participation constraint (9) must bind if she is hired by the university. If not, then a small increase in $e_{2}$ and/or decrease in $s_{2}$ will increase its utility without inducing her to exit the university. The administration's problem thus becomes

$$
\max _{\substack{e_{2} \in[0,1] \\ s_{2} \in\left[s_{L 2}, s_{H 2}\right]}} V_{A 2}\left(e_{2}, s_{2} ; \phi, \theta, p_{2}, k_{2}\right) \text { s.t. } V_{F 2}\left(e_{2}, s_{2}, \phi, p_{2}, k_{2}\right)=\bar{U}_{F 2}\left(\phi, p_{2}, k_{2}\right),
$$

or choose the point $\left(e_{2}, S_{2}\left(e_{2} ; \phi, p_{2}, k_{2}\right)\right)$ on her participation constraint that maximizes its utility.

Theorem 6 If (10) and (11) hold, and if $V_{F 2}\left(e_{2}, s_{2}, \phi, p_{2}, k_{2}\right)$ is strictly quasi-concave, $V_{A 2}\left(e_{2}, s_{2} ; \phi, \theta, p_{2}, k_{2}\right)$ is strictly quasi-convex, $T^{\prime}\left(q_{2}\right) \frac{\partial q_{2}\left(0 ; \theta, p_{2}, k_{2}\right)}{\partial e_{2}}>$ $\frac{\partial S_{2}\left(0, \phi, p_{2}, k_{2}\right)}{\partial e_{2}}$, and $T^{\prime}\left(q_{2}\right) \frac{\partial q_{2}\left(1 ; \theta, p_{2}, k_{2}\right)}{\partial e_{2}}<\frac{\partial S_{2}\left(1, \phi, p_{2}, k_{2}\right)}{\partial e_{2}}$ for all $\left(\phi, p_{2}, k_{2}\right)$, then the solution to $(15)$ is interior, $e_{2}^{*}\left(\phi, \theta, p_{2}, k_{2}\right) \in(0,1)$ and $s_{2}^{*}\left(\phi, \theta, p_{2}, k_{2}\right) \in$ $\left(s_{L 2}, s_{H 2}\right)$, and is characterized by

$$
\frac{\partial S_{2}\left(e_{2}^{*}, \phi, p_{2}, k_{2}\right)}{\partial e_{2}}=T^{\prime}(q) \frac{\partial q_{2}\left(e_{2}^{*} ; \theta, p_{2}, k_{2}\right)}{\partial e_{2}} .
$$

If the indifference curves for the researcher and administration have the correct curvature, and corner solutions at $e_{2}=0$ and $e_{2}=1$ are excluded, then the solution must be interior. The assumption that its indifference 
curve at $\left(e_{2}, s_{2}\right)=\left(0, s_{L 2}\right)$ is steeper than her participation constraint there implies that its utility increases if it pays her the higher salary required to induce her to teach. Because this implies she spends less time in research, its utility increases only if tuition revenue increases more than the increase in salary. As it continues to increase her salary to induce her to teach more, its gains in net income from higher tuition revenue decline. Recalling (8), equilibrium occurs when her salary and teaching load have increased to the point that these two effects offset each other, so that her marginal rate of substitution between research and income is equal to her marginal revenue product in education. This is depicted in Figure 1, where its utility increases as the outcome moves southeast, and its indifference curves are strictly concave. Note, however, that $I_{A 2}\left(e_{2} ; \phi, \theta, p_{2}, k_{2}, v\right)$ need not be concave. The secondorder sufficient conditions are satisfied as long as its indifference curve is concave, or at least no more convex than her participation constraint.

\subsection{Comparative Statics Results}

Unsurprisingly, comparative statics results are difficult to obtain with general utility functions. Nevertheless, several general results are straightforward.

Theorem 7 In static equilibrium, an increase in either knowledge stock or the researcher's share of license income increases her utility. A decrease in the portion of patentable knowledge disseminated has no effect on her utility but decreases the administration's utility.

Because the researcher's reservation utility $\bar{U}_{F 2}\left(\phi, p_{2}, k_{2}\right)$ is increasing in its arguments, and she must receive at least this much utility in equilibrium, an increase in $\phi, p_{2}$, or $k_{2}$ must increase her equilibrium utility (whether she remains in the university or exits). Because the researcher's utility within or without the university does not depend on the fraction of patentable knowledge disseminated, a change in $\theta$ has no effect on her equilibrium utility. However, the administration's utility $V_{A 2}\left(e_{2}, s_{2} ; \phi, \theta, p_{2}, k_{2}\right)$ is increasing in $\theta$ by Theorem 5 , so a decrease in $\theta$ reduce its equilibrium utility.

Some sensible, additional assumptions on reservation utility lead to more precise results. For example, recall that the knowledge stocks enter the researcher's preferences as measures of the prestige associated with successful past research. Thus, for an increase in $k_{2}$ to increase researcher utility more outside the university, it would have to be the case that this increase in her scientific knowledge stock would bring her more prestige outside the university. A priori, this seems unlikely. If she does decide to exit this university, 
her options would typically be another university, an existing firm, or a start-up firm. One typically thinks that the private sector values patentable research more highly, or at least no less highly. Thus, it is reasonable to assume that an increase in the stock of scientific knowledge from her first period research increases her utility from working in the university at least as much as her utility outside, $\frac{\partial V_{F 2}}{\partial k_{2}} \geq \frac{\partial \bar{U}_{F 2}}{\partial k_{2}}$, so $\frac{\partial S_{2}}{\partial k_{2}} \leq 0$ by Theorem 4 . Similarly, it is reasonable to assume that an increase in her stock of patentable knowledge increases her utility outside the university at least as much as in the university, $\frac{\partial V_{F 2}}{\partial p_{2}} \leq \frac{\partial \bar{U}_{F 2}}{\partial p_{2}}$, so $\frac{\partial S_{2}}{\partial p_{2}} \geq 0$ by Theorem 4 . Finally, because the researcher earns her share of license income whether she works for the university or not, a change in this share should not change her utility within the university compared to that outside, $\frac{\partial V_{F 2}}{\partial \phi}=\frac{\partial \bar{U}_{F 2}}{\partial \phi}$, so $\frac{\partial S_{2}}{\partial \phi}=0$ by Theorem 4 . The next result follows immediately from this and our assumption that the quality of education is increasing in all of its arguments.

Theorem 8 In static equilibrium: (i) If the researcher's prestige from discoveries that contribute to scientific knowledge is greater within the university, then an increase in the stock of that knowledge either decreases the salary or increases the teaching load or both. If the prestige from patentable knowledge is greater outside the university, then an increase in the stock of that knowledge either increases the salary or decreases the teaching load or both. In either case, if the teaching load does not decrease, the quality of education increases. If it does decrease, the effect on the quality of education is ambiguous.

(ii) If her license income is the same wherever she works, then an increase in her share either changes the salary and teaching load in same direction or has no effect on them. The quality of education decreases (increases) if and only if the teaching load decreases (increases).

(iii) A decrease in the portion of patentable knowledge disseminated either changes the salary and teaching load in the same direction or has no effect on them. If the teaching load does not increase, the quality of education decreases. If it does increase, the effect on the quality of education is ambiguous.

The effects on the salary and teaching load can be easily seen in Figure 1. If her prestige from basic research is greater within the university, then an increase in $k_{2}$ shifts $S_{2}\left(e_{2}, \phi, p_{2}, k_{2}\right)$ down, and the administration can pay her a lower salary and/or require a higher teaching load without inducing her to exit. Typically, we expect both a lower salary and higher teaching load. Because the quality of education $Q\left(e_{2} ; \theta p_{2}, k_{2}\right)$ is increasing in $k_{2}$ and 
$e_{2}$, we expect a higher quality of education. The administration has an incentive to pay a lower salary, and might pay a salary so much lower that it must require a lower teaching load as well, in which case the effect on the quality of education is ambiguous. However, it also may pay a higher salary in order to require an even higher teaching load and produce a higher quality of education.

If her prestige from applied research is greater outside the university, then an increase in $p_{2}$ shifts $S_{2}\left(e_{2}, \phi, p_{2}, k_{2}\right)$ up, and the administration must pay her a higher salary and/or require a lower teaching load to prevent her from exiting. Typically, we expect a higher salary and a lower teaching load. Because the quality of education is increasing in $p_{2}$ and $e_{2}$, the effect on the quality of education is ambiguous. A lower salary is possible, but only if her teaching load is also much lower. A higher teaching load is possible, in which case the quality of education increases, but only if her salary is also much higher.

If license income is the same inside or outside the university, then an increase in $\phi$ shifts both indifference maps, but the participation constraint (9) still binds at the original equilibrium point (i.e., the new participation constraint passes through the old equilibrium point). However, because the indifference curves through that point are associated with different levels of utility (her utility is higher and its is lower), their curvatures need not be the same as those of the indifference curves through that point before the change in $\phi$. Nevertheless, because the new participation constraint must also be positively sloped, the salary and teaching loads must move in the same direction, if they change at all. Because the quality of education is increasing in $e_{2}$ but does not depend on $\phi$, the quality of education is higher if and only if the teaching load is higher. While a decrease in $\theta$ does not affect the participation constraint, it does affect the quality of education and therefore administration utility. As with a change in $\phi$, the slopes of the indifference curves imply that if the teaching load and salary change, they must move in the same direction. Because the quality of education is increasing in $e_{2}$ and $\theta$, the effect on the quality of education is ambiguous. However, if the teaching load is lower, or no higher, then the quality of education must decrease.

Finally, suppose $V_{F 2}\left(e_{2}, s_{2}, \phi, p_{2}, k_{2}\right)$ and $V_{A 2}\left(e_{2}, s_{2} ; \phi, \theta, p_{2}, k_{2}\right)$ are homothetic with respect to $\left(e_{2}, s_{2}\right)$. That is, the corresponding indifference curves $I_{F 2}\left(e_{2}, \phi, p_{2}, k_{2}, v\right)$ and $I_{A 2}\left(e_{2}, \phi, \theta, p_{2}, k_{2}, v\right)$ have the same slope at any point $\left(e_{2}, s_{2}\right)$ on a negatively sloped ray emanating from the point $\left(e_{2}, s_{2}\right)=(1,0)$. Then an increase in $k_{2}$ decreases the salary and increases the teaching load, an increase in $p_{2}$ increases the salary and decreases the 
teaching load, and an increase in $\phi$ or $\theta$ has no effect on the salary and teaching load.

\section{The Dynamic Equilibrium}

\subsection{The Faculty Researcher's Problem}

The researcher's problem in period one, if she does not leave the university, is to allocate time between basic and applied research to maximize the present discounted value of her utility over both periods, subject to her periodone time constraint and income, the knowledge production functions, and the period-two equilibrium values. First, given her period-two equilibrium utility

$$
V_{F 2}\left(e_{2}^{*}, s_{2}^{*}, \phi, p_{2}, k_{2}\right)=\bar{U}_{F 2}\left(\phi, p_{2}, k_{2}\right),
$$

her total discounted utility over both periods is

$$
W_{F}\left(a_{1}, b_{1} ; s_{1}, \phi, p_{1}, k_{1}\right)=U_{F}\left(a_{1}, b_{1}, Y_{F 1}, p_{1}, k_{1}\right)+\delta \bar{U}_{F 2}\left(\phi, p_{2}, k_{2}\right),
$$

where $a_{1}+b_{1}=1-e_{1}, Y_{F 1}=s_{1}+\phi L\left(p_{1}\right), p_{2}=P\left(a_{1}, b_{1} ; p_{1}, k_{1}\right), k_{2}=$ $K\left(a_{1}, b_{1} ; p_{1}, k_{1}\right)$, and $\delta \in(0,1)$ is the discount factor. We define "composite" marginal utilities of $W_{F}$ with respect to its arguments, $\frac{\partial W_{F}}{\partial x}$ for $x=a_{1}, b_{1}, s_{1}, \phi, p_{1}, k_{1}$, which we assume are positive. We also define "composite" marginal rates of substitution, $M_{x y}\left(a_{1}, b_{1} ; s, \phi, p_{1}, k_{1}\right)=\frac{\frac{\partial W_{F}}{\partial x}}{\frac{\partial W_{F}}{\partial y}}$ for $x, y=a_{1}, b_{1}, s_{1}, \phi, p_{1}, k_{1}(x \neq y)$. We finally assume that $W_{F}$ is strictly quasi-concave in $\left(a_{1}, b_{1}\right)$, and that the composite marginal rate of substitution of applied for basic research, $M_{a b}\left(a_{1}, b_{1} ; s, \phi, p_{1}, k_{1}\right)$, is decreasing in $a_{1}$ and increasing in $b_{1}$.

Her problem, if she remains in the university in period one, is then

$$
\max _{a_{1} \geq 0, b_{1} \geq 0} W_{F}\left(a_{1}, b_{1} ; s_{1}, \phi, p_{1}, k_{1}\right) \text { s.t. } a_{1}+b_{1}=1-e_{1} .
$$

Theorem 9 Let $a_{1}^{*}\left(e_{1}, s_{1}, \phi, p_{1}, k_{1}\right)$ and $b_{1}^{*}\left(e_{1}, s_{1}, \phi, p_{1}, k_{1}\right)$ solve the researcher's optimization problem (18). Then the researcher specializes in basic research, $a_{1}^{*}=0$ and $b_{1}^{*}=1-e_{1}$, if

$$
\frac{\partial W_{F}\left(0,1-e_{1} ; s_{1}, \phi, p_{1}, k_{1}\right)}{\partial b_{1}} \geq \frac{\partial W_{F}\left(0,1-e_{1} ; s_{1}, \phi, p_{1}, k_{1}\right)}{\partial a_{1}},
$$

specializes in applied research, $a^{*}=1-e_{1}$ and $b^{*}=0$, if

$$
\frac{\partial W_{F}\left(1-e_{1}, 0 ; s_{1}, \phi, p_{1}, k_{1}\right)}{\partial a_{1}} \geq \frac{\partial W_{F}\left(1-e_{1}, 0 ; s_{1}, \phi, p_{1}, k_{1}\right)}{\partial b_{1}} .
$$


and devotes effort to each type of research, $a_{1}^{*}>0, b_{1}^{*}>0$, and $a_{1}^{*}+b_{1}^{*}=$ $1-e_{1}$, if (19) and (20) do not hold, in which case

$$
\frac{\partial W_{F}\left(a_{1}^{*}, b_{1}^{*} ; s_{1}, \phi, p_{1}, k_{1}\right)}{\partial a_{1}}=\frac{\partial W_{F}\left(a_{1}^{*}, b_{1}^{*} ; s_{1}, \phi, p_{1}, k_{1}\right)}{\partial b_{1}} .
$$

Observe that the composite marginal utilities of time in research are

$$
\frac{\partial W_{F}}{\partial a_{1}}=\frac{\partial U_{F}}{\partial a_{1}}+\delta\left(\frac{\partial \bar{U}_{F 2}}{\partial p_{2}} \frac{\partial P}{\partial a_{1}}+\frac{\partial \bar{U}_{F 2}}{\partial k_{2}} \frac{\partial K}{\partial a_{1}}\right)
$$

and

$$
\frac{\partial W_{F}}{\partial b_{1}}=\frac{\partial U_{F}}{\partial b_{1}}+\delta\left(\frac{\partial \bar{U}_{F 2}}{\partial p_{2}} \frac{\partial P}{\partial b_{1}}+\frac{\partial \bar{U}_{F 2}}{\partial k_{2}} \frac{\partial K}{\partial b_{1}}\right) .
$$

The first term on the right-hand side of (22) and (23) reflects the researcher's love for research and is a pure utility effect, while the bracketed term reflects the effect on future utility from her current research. Producing knowledge in period one has two effects on period-two utility. One is a pure "ego" effect showing the reputational effect associated with producing patentable and scientific knowledge. The other is a "love of money" associated with her ability to earn license income from producing patentable knowledge and to influence her salary by producing both scientific and patentable knowledge.

Hence, in a dynamic environment, the necessary condition for an interior equilibrium is more complex than the static condition that she allocate her time between applied and basic research to strike a balance between her love for each. Now she must allocate her time to strike a balance between her love for research, her love for money, and her ego.

This result also allows us to show the complexity of the response of the researcher to the Bayh-Dole Act and other similar policies. An increase in $\phi$ will induce her to reallocate time from basic to applied research if and only if it increases the composite marginal rate of substitution of applied for basic research, or

$$
\frac{\partial U_{F}}{\partial a_{1}}-\frac{\partial U_{F}}{\partial b_{1}}+\delta \frac{\partial \bar{U}_{F 2}}{\partial p_{2}}\left(\frac{\partial P}{\partial a_{1}}-\frac{\partial P}{\partial b_{1}}\right)+\delta \frac{\partial \bar{U}_{F 2}}{\partial k_{2}}\left(\frac{\partial K}{\partial a_{1}}-\frac{\partial K}{\partial b_{1}}\right)>0 .
$$

Because $\bar{U}_{F 2}$ is increasing in $\phi, p_{2}$, and $k_{2}$, an increase in $\phi$ does not increase $\frac{\partial W_{F}}{\partial a_{1}}-\frac{\partial W_{F}}{\partial b_{1}}$ unless one or more of the following holds: $\frac{\partial P}{\partial a_{1}}>\frac{\partial P}{\partial b_{1}}, \frac{\partial K}{\partial a_{1}}>\frac{\partial K}{\partial b_{1}}$, or $\frac{\partial U_{F}}{\partial a_{1}}>\frac{\partial U_{F}}{\partial b_{1}}$. Note that $\frac{\partial P}{\partial a_{1}}>\frac{\partial P}{\partial b_{1}}$ only if the first hour that is reallocated from basic to applied research results in a greater future stock of patentable knowledge. This is likely, a priori. However, this reallocation is also likely 
to result in a lower future stock of scientific knowledge, $\frac{\partial K}{\partial a_{1}}<\frac{\partial K}{\partial b_{1}}$. And, of course, if this researcher likes basic research more, then $\frac{\partial U_{F}}{\partial a_{1}}<\frac{\partial U_{F}}{\partial b_{1}}$ as well. Thus, this reallocation occurs if and only if the increase in total discounted utility from a greater future stock of patentable knowledge outweighs any decrease from a smaller future stock of scientific knowledge and less current time spent in basic research.

Two more points are worth noting. First, $\frac{\partial P}{\partial a_{1}}-\frac{\partial P}{\partial b_{1}}$ is lower the greater is the extent to which her research fits in the so-called "Pasteur's Quadrant," in which case a reallocation of time to applied research is less likely to occur because it is less likely to increase the stock of patentable knowledge. Second, a reallocation of time to applied research is also less likely to occur if her love of basic research is sufficient that she would specialize in it absent ego or income effects, $\frac{\partial U_{F}}{\partial a_{1}}<\frac{\partial U_{F}}{\partial b_{1}}$ at $b_{1}^{*}=1-e_{1}$.

The comparative statics results for the interior solution are analogous to those in the static case.

Theorem 10 In an interior solution to (18), an increase in time in education decreases time in both basic and applied research. A change in the salary, the share of license income, and either initial knowledge stock implies an increased allocation of time to applied research if and only if the composite marginal rate of substitution of applied for basic research increases.

The researcher's period-one indirect utility function is

$$
V_{F 1}\left(e_{1}, s_{1}, \phi, p_{1}, k_{1}\right)=W_{F}\left(a_{1}^{*}, b_{1}^{*} ; s_{1}, \phi, p_{1}, k_{1}\right)
$$

which for given utility, $v$, implicitly defines an indifference curve in $\left(e_{1}, s_{1}\right)$ space, $I_{F 1}\left(e_{1}, \phi, p_{1}, k_{1}, v\right)$, which embodies period-two equilibrium behavior and has slope equal to the composite marginal rate of substitution between either type of research and salary income,

$$
\frac{\partial I_{F 1}\left(e_{1}, \phi, p_{1}, k_{1}, v\right)}{\partial e_{1}}=\frac{\frac{\partial W_{F}}{\partial a_{1}}}{\frac{\partial W_{F}}{\partial s_{1}}}=\frac{\frac{\partial W_{F}}{\partial b_{1}}}{\frac{\partial W_{F}}{\partial s_{1}}} .
$$

These indifference curves, including the specific one for which the participation constraint binds, have the same properties as in the static case.

If the researcher exits the university in period one, then her total discounted reservation utility from both periods is $\bar{U}_{F 1}\left(\phi, p_{1}, k_{1}, \delta\right),{ }^{5}$ which we

\footnotetext{
${ }^{5}$ We are implicitly assuming here that if she departs in period one, then the university replaces her and so she does not have the option of returning to this university in period two.
} 
assume is no less than her period-two reservation utility if she remains with the university in period one, but then departs in period two, $\bar{U}_{F 1}\left(\phi, p_{1}, k_{1}, \delta\right) \geq$ $\bar{U}_{F 2}\left(\phi, p_{1}, k_{1}\right)$. As in the static case, she remains in the university in period one only if her participation constraint is satisfied,

$$
V_{F 1}\left(e_{1}, s_{1}, \phi, p_{1}, k_{1}\right) \geq \bar{U}_{F 1}\left(\phi, p_{1}, k_{1}, \delta\right) .
$$

Theorem 11 In period one, the researcher's indirect utility is increasing in her salary, her share of license income, and both initial knowledge stocks, but decreasing in her time spent in education in period one: $\frac{\partial V_{F 1}}{\partial s_{1}}>0, \frac{\partial V_{F 1}}{\partial \phi}>0$,

$\frac{\partial V_{F 1}}{\partial p_{1}}>0, \frac{\partial V_{F 1}}{\partial k_{1}}>0$, and $\frac{\partial V_{F 1}}{\partial e_{1}}<0$. Thus, a researcher's typical indifference curve in $\left(e_{1}, s_{1}\right)$ space is positively sloped and decreasing in her share of license income and both initial knowledge stocks. Furthermore, if there exist $s_{L 1}$ and $s_{H 1}$ such that $s_{H 1}>s_{L 1}>0$,

$$
V_{F 1}\left(0, s_{L 1}, \phi, p_{1}, k_{1}\right)=\bar{U}_{F 1}\left(\phi, p_{1}, k_{1}, \delta\right)
$$

and

$$
V_{F 1}\left(1, s_{H 1}, \phi, p_{1}, k_{1}\right)=\bar{U}_{F 1}\left(\phi, p_{1}, k_{1}, \delta\right) .
$$

then $V_{F 1}\left(e_{1}, s_{1}, \phi, p_{1}, k_{1}\right)=\bar{U}_{F 1}\left(\phi, p_{1}, k_{1}, \delta\right)$ defines a function $S_{1}\left(e_{1}, \phi, p_{1}, k_{1}, \delta\right)$, where $S_{1}$ maps $[0,1]$ onto $\left[s_{L 1}, s_{H 1}\right]$, such that the participation constraint binds for all $\left(e_{1}, s_{1}\right)=\left(e_{1}, S_{1}\left(e_{1}, \phi, p_{1}, k_{1}, \delta\right)\right)$ and:

(i) $S_{1}$ is increasing in the time spent in education, $\frac{\partial S_{1}}{\partial e_{1}}>0$.

(ii) $S_{1}$ is increasing (decreasing, constant) in the inventor's share or either initial knowledge stock if and only if the effect of a change in that parameter on her reservation utility is greater than (less than, equal to) that on her utility within the university, $\frac{\partial S_{1}}{\partial x}>(<,=) 0$ if and only if $\frac{\partial \bar{U}_{F 1}}{\partial x}>(<,=) \frac{\partial V_{F 1}}{\partial x}$ for $x=\phi, p_{2}, k_{2}$.

\subsection{The Administration's Problem}

The administration's total discounted utility over both periods is

$$
W_{A}\left(e_{1}, s_{1} ; \phi, \theta, p_{1}, k_{1}\right)=V_{A 1}\left(e_{1}, s_{1} ; \phi, \theta, p_{1}, k_{1}\right)+\delta V_{A 2}^{*}\left(\phi, \theta, p_{2}, k_{2}\right),
$$

where $V_{A 2}^{*}\left(\phi, \theta, p_{2}, k_{2}\right)=V_{A 2}\left(e_{2}^{*}, s_{2}^{*} ; \phi, \theta, p_{2}, k_{2}\right)$ is period-two equilibrium utility and $q_{1}=Q\left(e_{1} ; \theta p_{1}, k_{1}\right)$ is substituted into its current income $Y_{A 1}$ to obtain current utility $V_{A 1}\left(e_{1}, s_{1} ; \phi, \theta, p_{1}, k_{1}\right)$. For given utility, $v$, the equation $V_{A 1}\left(e_{1}, s_{1} ; \phi, \theta, p_{1}, k_{1}\right)=v$ implicitly defines its indifference curve in 
$\left(e_{1}, s_{1}\right)$ space, $I_{A 1}\left(e_{1}, \phi, \theta, p_{1}, k_{1}, v\right)$, which embodies period-two equilibrium behavior and has slope

$$
\frac{\partial I_{A 1}\left(e_{1} ; \phi, \theta, p_{1}, k_{1}, v\right)}{\partial e_{1}}=-\frac{\frac{\partial W_{A}\left(e_{1}, s_{1} ; \phi, \theta, p_{1}, k_{1}\right)}{\partial e_{1}}}{\frac{\partial W_{A}\left(e_{1}, s_{1} ; \phi, \theta, p_{1}, k_{1}\right)}{\partial s_{1}}} .
$$

Theorem 12 The administration's total discounted utility is increasing in the portion of patentable knowledge disseminated in education, $\frac{\partial W_{A}}{\partial \theta}>0$, but ambiguously related to its other arguments. However, if the period-two effects of knowledge production are not perverse, then its total discounted utility is increasing in the time spent by the researcher in education and both initial knowledge stocks, but decreasing in her salary and her share of license income: $\frac{\partial W_{A}}{\partial e_{1}}>0, \frac{\partial W_{A}}{\partial k_{1}}>0$, and $\frac{\partial W_{A}}{\partial p_{1}}>0$, but $\frac{\partial W_{A}}{\partial s_{1}}<0$ and $\frac{\partial W_{A}}{\partial \phi}<0$. In this case, its indifference curve in $\left(e_{1}, s_{1}\right)$ space is positively sloped, increasing in both initial knowledge stocks and the portion of patentable knowledge disseminated, but decreasing in her share of license income.

The only general result is that its total discounted utility is increasing in the portion of patentable knowledge disseminated in education. This does not cause the researcher to change her allocation of time between applied and basic research, but instead merely causes a change the quality of education and tuition revenue. Thus, if recent legislation and policy changes reduce the dissemination of patentable knowledge, then ceteris paribus educational quality and administration utility decrease.

Unlike the static case, now the marginal contributions of her teaching load and salary to its total discounted utility depend not just on their effects on its current net income, but also their effects on knowledge production, and thus its future license income and prestige. This explains the difficulty in obtaining unambiguous results when the researcher's optimal behavior is taken into account. For example, if it increases her current teaching load, then the direct effect is to increase the current quality of education, as $\frac{\partial Q}{\partial e_{1}}>0$, and so its tuition revenue and utility. However, from Theorem 10, this also decreases the time she spends in both applied and basic research, and so the production of both types of knowledge, which in turn tends to decrease its total discounted utility by decreasing its future tuition revenue, licensing income, and prestige. Although it seems unlikely, or even perverse, these "second-order" effects could dominate and lower its total discounted utility. Next, an increase in her current salary has the direct effect of reducing its current net income and utility, but also may induce a change in her research behavior. This might lead her to allocate more time to basic 
research, thus increasing the production of scientific knowledge, but decreasing the production of patentable knowledge and the license income from it. Again, conceivably the latter losses could dominate.

In what follows, therefore, we assume that its total discounted utility is increasing in the researcher's time in education and decreasing in her salary over the relevant range, $\frac{\partial W_{A}}{\partial e_{1}}>0$ and $\frac{\partial W_{A}}{\partial s_{1}}<0$ for $e_{1} \in[0,1]$ and $s_{1} \in\left[s_{L 1}, s_{H 1}\right]$, so its indifference curves are also positively sloped. It then follows from the preceding theorem that her participation constraint (27) must bind if she is hired by the university. Its problem thus becomes

$$
\max _{\substack{e_{1} \in[0,1] \\ s_{1} \in\left[s_{L 1}, s_{H 1}\right]}} W_{A}\left(e_{1}, s_{1} ; \phi, \theta, p_{1}, k_{1}\right) \text { s.t. } V_{F 1}\left(e_{1}, s_{1}, \phi, p_{1}, k_{1}\right)=\bar{U}_{F 1}\left(\phi, p_{1}, k_{1}, \delta\right),
$$

or choose the point $\left(e_{1}, S_{1}\left(e_{1}, \phi, p_{1}, k_{1}, \delta\right)\right)$ on her participation constraint that maximizes its total discounted utility. This dynamic equilibrium outcome is similar to that depicted in Figure 1 for the static case.

Theorem 13 Assume that (28) and (29) hold, that $V_{F 1}\left(e_{1}, s_{1}, \phi, p_{1}, k_{1}\right)$ is strictly quasi-concave in $\left(e_{1}, s_{1}\right)$, and that $W_{A}\left(e_{1}, s_{1} ; \phi, \theta, p_{1}, k_{1}\right)$ is increasing in $e_{1}$ and decreasing in $s_{1}$ for $e_{1} \in[0,1]$ and $s_{1} \in\left[s_{L 1}, s_{H 1}\right]$. Also assume that, for all $\left(\phi, \theta, p_{1}, k_{1}, v\right), \frac{\partial I_{A 1}\left(0 ; \phi, \theta, p_{1}, k_{1}, v\right)}{\partial e_{1}}>\frac{\partial S_{1}\left(0 ; \phi, p_{1}, k_{1}, \delta\right)}{\partial e_{1}}$, $\frac{\partial I_{A 1}\left(1 ; \phi, \theta, p_{1}, k_{1}, v\right)}{\partial e_{1}}<\frac{\partial S_{1}\left(1 ; \phi, p_{1}, k_{1}, \delta\right)}{\partial e_{1}}$, and $\frac{\partial^{2} I_{A 1}\left(e_{1} ; \phi, \theta, p_{1}, k_{1}, v\right)}{\partial e_{1}^{2}}>\frac{\partial^{2} S_{1}\left(e_{1} ; \phi, p_{1}, k_{1}, \delta\right)}{\partial e_{1}^{2}}$ for all $e_{1} \in[0,1]$. Then the solution to (32) is interior, $e_{1}^{*}\left(\phi, \theta, p_{1}, k_{1}\right) \in(0,1)$ and $s_{1}^{*}\left(\phi, \theta, p_{1}, k_{1}\right) \in\left(s_{L 1}, s_{H 1}\right)$, and is characterized by

$$
\frac{\partial S_{1}\left(e_{1}^{*}, \phi, p_{1}, k_{1}, \delta\right)}{\partial e_{1}}=\frac{\partial I_{A 1}\left(e_{1}^{*} ; \phi, \theta, p_{1}, k_{1}, v^{*}\right)}{\partial e_{1}}
$$

where $v^{*}=V_{A 1}\left(e_{1}^{*}, s_{1}^{*} ; \phi, \theta, p_{1}, k_{1}\right)$.

As in the static case, the assumption that its indifference curve at $e_{1}=0$ is steeper than her participation constraint implies that its total discounted utility increases if it pays her the higher current salary required to induce her to teach more. Unlike the static case, however, now this reduction of current time spent in research also reduces future knowledge stocks, license income, and prestige. Thus, its total discounted utility increases only if the increased teaching results in an increase in current tuition revenue that is large enough to overwhelm these future effects. Equilibrium is attained when her salary and teaching load have increased enough that the administration's willingness to pay her to teach an additional hour equals her composite marginal rate of substitution between research and income. 


\subsection{Comparative Statics Results}

Finally, we are again interested in the period-one equilibrium teaching load and salary, and the corresponding equilibrium total discounted utilities, $V_{F 1}\left(e_{1}^{*}, s_{1}^{*}, \phi, p_{1}, k_{1}\right)$ and $W_{A}\left(e_{1}^{*}, s_{1}^{*} ; \phi, \theta, p_{1}, k_{1}\right)$. As in the static case, results are difficult to obtain without specific utility functions.

Theorem 14 In dynamic equilibrium, an increase in either initial knowledge stock or the researcher's share of license income increases her total discounted utility. A decrease in the portion of patentable knowledge disseminated has no effect on her total discounted utility, but decreases the administration's total discounted utility.

As in the static case, because her total discounted reservation utility $\bar{U}_{F 1}\left(\phi, p_{1}, k_{1}, \delta\right)$ is increasing in $\phi, p_{1}$, and $k_{1}$, an increase in any of them must increase her equilibrium total discounted utility whether or not she remains in the university. Because her utility inside or outside the university does not depend on $\theta$, a change in it has no effect on her equilibrium utility. However, by Theorem 11, a decrease in $\theta$ decreases the administration's equilibrium total discounted utility.

Again, given Theorem 11, reasonable assumptions on her utility lead to more precise results.

Theorem 15 The comparative static effects of changes in $\phi, \theta, p_{1}$, and $k_{1}$ on period-one equilibrium values are qualitatively the same as the results stated in Theorem 8.

As in the static case, if her prestige from scientific knowledge is greater within the university, then an increase in $k_{1}$ allows the administration to pay her a lower salary and/or require a higher teaching load in period-one. If her prestige from patentable knowledge is greater outside the university, then an increase in $p_{1}$ allows it to pay her a higher salary and/or require a lower teaching load in period-one. If license income is the same inside or outside the university, then an increase in $\phi$ implies her salary and teaching load in period-one must move in the same direction, if they change at all. Similarly, a decrease in $\theta$ implies her salary and teaching load in period-one move in the same direction, if they change at all. Finally, if $V_{F 1}\left(e_{1}, s_{1}, \phi, p_{1}, k_{1}\right)$ and $W_{A}\left(e_{1}, s_{1} ; \phi, \theta, p_{1}, k_{1}\right)$ are homothetic with respect to $\left(e_{1}, s_{1}\right)$, then in period one an increase in $k_{1}$ decreases the salary and increases the teaching load, an increase in $p_{1}$ increases the salary and decreases the teaching load, and an increase in $\phi$ or $\theta$ has no effect on the salary and teaching load. 


\section{Concluding Remarks}

This paper has sought to add rigor to the rhetoric on whether policy-makers should be concerned about patent policy changes that created incentives for commercialization of university research which also might be detrimental to basic science and the quality of education. We developed a dynamic, theoretical model in which these policy changes are equivalent to an increase in the stock of patentable knowledge, an increase in the researcher's share of license income, and a decrease in the fraction of patentable knowledge that can be used in education. One concern is that faculty might be diverted from academic research and teaching to applied research. We showed that, if faculty viewed both basic research and applied research as goods, then whether these policy changes have resulted in a substitution of applied for basic research depends on how they have influenced individual researchers' marginal rates of substitution between these types of research and between either type of research and income. It is therefore not obvious how these policy changes affected the allocation of time between applied and basic research. This is an empirical question that awaits further research.

Another concern focuses on the effects of these policy changes on the quality of education. We also show that the administration chooses the researcher's salary and teaching load so that her marginal revenue product in education equals her marginal rate of substitution between research and income, and so that she earns only her reservation utility. Under our assumptions, the effects of these policy changes on the quality of education depend on how they influence the teaching load and the amount of patentable knowledge used in education. Generally, changes in the stock of patentable knowledge, the researcher's share of license income, and the fraction of patentable knowledge that can be used in education have an ambiguous effect on the teaching load, and thus the quality of education. The effect of these policies on the amount of patentable knowledge used in education is itself ambiguous because although the stock of patentable knowledge increases, the fraction of it that is used in education decreases.

In the case of homothetic preferences, the comparative statics on the teaching load are not ambiguous. An increase in the stock of patentable knowledge has a direct effect of increasing quality, but also an indirect effect, through decreasing the teaching load, of decreasing quality. A reduction in the fraction of patentable knowledge used in education has the direct effect of decreasing quality and has no effect on the teaching load. Therefore the overall effect of policy changes regarding patentable knowledge is ambiguous, although the net effect is more likely to be negative (and it definitely is if the 
amount of patentable knowledge used in education does not increase enough to offset the negative effects of a decreased teaching load). Finally, in this case an increase in the researcher's share of license income has no effect on quality because it has no effect on the teaching load.

There remain unexplored issues of interest. For example, if effort in education is unobservable, then there is a moral hazard problem which the administration must deal with in designing the researcher's contract. A more detailed analysis of the researcher's outside options might also be of interest, particularly because universities are increasingly allowing faculty to take sabbaticals to develop their inventions in start-up ventures. In the latter case, administrations must be careful in designing contracts that take into account potential conflicts of interest and commitment.

\section{References}

Association of University Technology Managers, AUTM Licensing Survey, 1991 and 1998.

Beath, J., R. Owen, J. Poyago-Theotoky, D. Ulph. "Optimal Incentives for Income-Generation within Universities," International Journal of Industrial Organization 21, Nov. 2003, 1301-1322.

Blumenthal, D., E. Campbell, M. Anderson, N. Causino, and K. Louis, 1997, "Withholding Re-search Results in Academic Life Science: Evidence from a National Survey of Faculty," Journal of the American Medical Association 277(15), 1224-1228.

Borooah, Vani K. "Modelling Institutional behaviour: A Microeconomic Analysis of University Management," Public Choice, 1994, 81, 101-124.

Cockburn, I., R. Henderson and S. Stern. "Balancing Incentives: The Tension Between Basic and Applied Research," January 1999, NBER Working Paper 6882.

Cohen, W. M., R. Florida, L. Randazzese, and J. Walsh. "Industry and the Academy: Uneasy Partners in the Cause of Technological Advance," in Challenges to Research Universities edited by Roger Noll. Washington, D.C.: The Brookings Institution, 1998.

Congressional Record, Testimony of Teri Willey, Senate Committee on Federal Funding, April 15, 1999.

Del Ray, Elena, "Teaching versus Research: A Model of State University Competition," Journal Of Urban Economics, 2001, 49, 356-373.

Gallini, N., "The Economics of Patents: Lessons from Recent U.S. Patent Reform," Journal of Economic Perspectives, 2002, 16(2), 131-154. 
Griliches, Zvi. "Productivity Puzzles and R\&D: Another Nonexplanation." Journal of Economic Perspectives 2, Fall 1988, 9-21

Hagstrom, W. The Scientific Community. New York: Basic Books, 1965.

Henderson, Rebecca, Adam Jaffe and Trajtenberg, "Universities as a Source of Commercial Technology: A Detailed Analysis of University Patenting, 1965-1988, Review of Economics and Statistics (1998), 119-127.

Holmstrom, B., "Multitask Principal-Agent Analysis: Incentive Contract, Assets Ownership, and Job Design," Journal of Law, Economics, and Organization 1991, 24-52.

Jaffe, Adam, Manuel Trajtenberg and Rebecca Henderson, "Geographic Localization of Knowledge Spillovers as Evidenced by Patent Citations," Quarterly Journal of Economics, 1993.

Jensen, R., J. Thursby, and M. Thursby, "The Disclosure and Licensing of University Inventions: 'The best we can do with the $\mathrm{s}^{* *} \mathrm{t}$ we get to work with," International Journal of Industrial Organization 21, Nov. 2003, 12711300 .

Jensen, R. and M. Thursby. "Proofs and Prototypes for Sale: The Licensing of University Inventions." American Economic Review, 2001, 91, 240-259.

Kuhn, T.. The Structure of Scientific Revolutions. Chicago: University of Chicago Press, 1970.

Levin, S. and P. Stephan. "Research Productivity over the Life Cycle: Evidence for American Scientists," American Economic Review, 1991, 81, 114-132.

Louis, K., L. Jones, M. Anderson, D. Blumenthal, and E. Campbell, "Entrepreneurship, Secrecy, and Productivity: A Comparison of Clinical and Non-Clinical Life Sciences Faculty," The Journal of Technology Transfer 2001, 26, 233-245.

Mansfield, E. "Academic Research Underlying Industrial Innovations: Sources, Characteristics, and Financing." The Review of Economics and Statistics 1995, 55-65.27.

Morgan, R., N. Kannankutty, and D. Strickland. 1997. Future directions for university -based engineering research. ASEE PRISM 6 (7): 33-36.

Mowery, D., R. Nelson, B. Sampat and A. Ziedonis, "The Growth of Patenting and Licensing by U.S. Universities: An Assessment of the effects of the Bayh-Dole Act of 1980," Research Policy 2001a, 30, 99-119.

Mowery, D. and B. Sampat, "University Patents and Patent Policy Debates in the USA, 1925-1980," Industrial and Corporate Change 2001b,10, 781-814. 
Nelson, R. "What is Private and What is Public about Technology?" Science, Technology and Human Values, 1989, 14(3), 229-241.

Osano, Hiroshi. "Basic Research and Applied R\&D in a Model of Endogenous Economic Growth. Osaka Economic Papers, September 1992, 42(1), 144-167.

Press, Eyal, and J. Washburn, "The Kept University," Atlantic Monthly, March 2000.

Rahm, Dianne. 1994. U.S. universities and technology transfer: Perspectives of academic administrators and researchers. Industry and Higher Education, 72-78.

Stephan, P., "The Economics of Science." Journal of Economic Literature 1996, 34(3), 1199-1235.

Stephan, P., "Educational Implications of University-Industry Technology Transfer," Journal of Technology Transfer 2001, 26(3), 199-205.

Stephan, P. and S. Levin, "Property Rights and Entrepreneurship in Science," Small Business Economics 1996, 8, 177-188.

Stern, S., "Do Scientists Pay to be Scientists?," Management Science, June 2004, 50(6), 835-853.

Thursby, J., R. Jensen and M. Thursby, "Objectives, Characteristics and Outcomes of University Licensing: A Survey of Major U.S. Universities," Journal of Technology Transfer, January, 2001, 59-72.

Thursby, J., and M.C. Thursby, "Who is Selling the Ivory Tower? Sources of Growth in University Licensing," Management Science 2002, 48(1), 90104.

Thursby, J., and M.C. Thursby, "Patterns of Research and Licensing Activity of Science and Engineering Faculty," in Ehrenberg, Ronald and Paula Stephan, eds., Science and the University, Madison: University of Wisconsin Press, 2004 forthcoming.

Zucker, L., M. Darby and J. Armstrong, "Intellectual Capital and the Firm: The Technology of Geographically Localized Knowledge Spillovers," NBER Working Paper \#4946 (1994).

Zucker, L., M. Darby and M. Brewer, "Intellectual Capital and the Birth of U.S. Biotechnology Enterprises," American Economic Review, March 1998, 88 (1), 290-306. 


\section{Appendix}

\subsection{Proofs of Theorems 1, 2, 3, and 4}

To prove Theorem 1 , let $N_{F 2}\left(b_{2} ; Y_{F 2}, p_{2}, k_{2}\right)=U_{F}\left(1-e_{2}-b_{2}, b_{2} ; Y_{F 2}, p_{2}, k_{2}\right)$. Then because $\frac{\partial N_{F 2}}{\partial b_{2}}=-\frac{\partial U_{F}}{\partial a_{2}}+\frac{\partial U_{F}}{\partial b_{2}}$ and $\frac{\partial^{2} N_{F 2}}{\partial b_{2}^{2}}=\frac{\partial^{2} U_{F}}{\partial a_{2}^{2}}+\frac{\partial^{2} U_{F}}{\partial b_{2}^{2}}-2 \frac{\partial^{2} U_{F}}{\partial a_{2} \partial b_{2}}<0$, it follows that $N_{F 2}$ is maximized at $b_{2}=0$ if $\frac{\partial N_{F 2}(0)}{\partial b_{2}}=-\frac{\partial U_{F}\left(1-e_{2}, 0 ; Y_{F 2}, p_{2}, k_{2}\right)}{\partial a_{2}}+$ $\frac{\partial U_{F}\left(1-e_{2}, 0 ; Y_{F 2}, p_{2}, k_{2}\right)}{\partial b_{2}} \leq 0$, or $m_{a b}\left(1-e_{2}, 0 ; Y_{F 2}, p_{2}, k_{2}\right) \geq 1$, and at $b_{2}=1-e_{2}$ if $\frac{\partial N_{F 2}\left(1-e_{2}\right)}{\partial b_{2}}=-\frac{\partial U_{F}\left(0,1-e_{2} ; Y_{F 2}, p_{2}, k_{2}\right)}{\partial a_{2}}+\frac{\partial U_{F}\left(0,1-e_{2} ; Y_{F 2}, p_{2}, k_{2}\right)}{\partial b_{2}} \geq 0$, or $m_{a b}(1-$ $\left.e_{2}, 0 ; Y_{F 2}, p_{2}, k_{2}\right) \leq 1$. Otherwise, the solution is interior with $\frac{\partial N_{F 2}\left(b_{2}^{*}\right)}{\partial b_{2}}=$ $-\frac{\partial U_{F}\left(1-e_{2}-b_{2}^{*}, b_{2}^{*} ; Y_{F 2}, p_{2}, k_{2}\right)}{\partial a_{2}}+\frac{\partial U_{F}\left(1-e_{2}-b_{2}^{*}, b_{2}^{*} ; Y_{F 2}, p_{2}, k_{2}\right)}{\partial b_{2}}=0$, or $m_{a b}\left(1-e_{2}-\right.$ $\left.b_{2}^{*}, b_{2}^{*} ; Y_{F 2}, p_{2}, k_{2}\right)=1$.

To prove Theorem 2, recall $a_{2}^{*}=1-e_{2}-b_{2}^{*}$ implies the sign of $\frac{\partial a_{2}^{*}}{\partial x}$ is the sign of $-\frac{\partial b_{2}^{*}}{\partial x}$ for $x=s_{2}, \phi, p_{2}, k_{2}$, but the sign of $\frac{\partial a_{2}^{*}}{\partial e_{2}}$ is the sign of $-1-\frac{\partial b_{2}^{*}}{\partial e_{2}}$. Next, in an interior solution, $m_{a b}\left(1-e_{2}-b_{2}^{*}, b_{2}^{*} ; Y_{F 2}, p_{2}, k_{2}\right)=1$, so $\frac{\partial b_{2}^{*}}{\partial x}=-\frac{\frac{\partial m_{a b}}{\partial x}}{\frac{\partial m_{a b}}{\partial b_{2}}}$ where $\frac{\partial m_{a b}}{\partial b_{2}}=\frac{\partial m_{a b}}{\partial a_{2}}(-1)+\frac{\partial m_{a b}}{\partial b_{2}}>0$, which implies the sign of $\frac{\partial b_{2}^{*}}{\partial x}$ is the same as the sign of $-\frac{\partial m_{a b}}{\partial x}$, and the sign of $\frac{\partial a_{2}^{*}}{\partial x}$ is the same as the sign of $\frac{\partial m_{a b}}{\partial x}$. Hence, $\frac{\partial b_{2}^{*}}{\partial e_{2}}=\frac{-\frac{\partial m_{a b}}{\partial a_{2}}}{\frac{\partial m_{a b}}{\partial a_{2}}-\frac{\partial m_{a b}}{\partial b_{2}}}<0$, whence $\frac{\partial a^{*}}{\partial e_{2}}=-1-\frac{\partial b_{2}^{*}}{\partial e_{2}}=$ $\frac{\frac{\partial m_{a b}}{\partial b_{2}}}{\frac{\partial m_{a b}}{\partial a_{2}}-\frac{\partial m_{a b}}{\partial b_{2}}}<0$. Similarly, $\frac{\partial b_{2}^{*}}{\partial \phi}=\frac{\frac{\partial m_{a b}}{\partial Y_{F 2}} L\left(p_{2}\right)}{\frac{\partial m_{a b}}{\partial a_{2}}-\frac{\partial m_{a b}}{\partial b_{2}}}$ has the sign of $-\frac{\partial m_{a b}}{\partial Y_{F 2}}$ and $\frac{\partial a_{2}^{*}}{\partial \phi}$ has the sign of $\frac{\partial m_{a b}}{\partial Y_{F 2}}, \frac{\partial b_{2}^{*}}{\partial s_{2}}=\frac{\frac{\partial m_{a b}}{\partial Y_{F 2}}}{\frac{\partial m_{a b}}{\partial a_{2}}-\frac{\partial m_{a b}}{\partial b_{2}}}$ has the sign of $-\frac{\partial m_{a b}}{\partial Y_{F 2}}$ and $\frac{\partial a^{*}}{\partial s_{2}}$ has the sign of $\frac{\partial m_{a b}}{\partial Y_{F 2}}, \frac{\partial b_{2}^{*}}{\partial p_{2}}=\frac{\frac{\partial m_{a b}}{\partial Y_{F 2}} \phi L^{\prime}\left(p_{2}\right)+\frac{\partial m_{a b}}{\partial p_{2}}}{\frac{\partial m_{a b}}{\partial a_{2}}-\frac{\partial m_{a b}}{\partial b_{2}}}$ has the sign of $-\left[\frac{\partial m_{a b}}{\partial Y_{F 2}} \phi L^{\prime}\left(p_{2}\right)+\frac{\partial m_{a b}}{\partial p_{2}}\right]$ and $\frac{\partial a_{2}^{*}}{\partial p_{2}}$ has the sign of $\frac{\partial m_{a b}}{\partial Y_{F 2}} \phi L^{\prime}\left(p_{2}\right)+\frac{\partial m_{a b}}{\partial p_{2}}$, and $\frac{\partial b_{2}^{*}}{\partial k_{2}}=\frac{\frac{\partial m_{a b}}{\partial k_{2}}}{\frac{\partial m_{a b}}{\partial a_{2}}-\frac{\partial m_{a b}}{\partial b_{2}}}$ has the sign of $-\frac{\partial m_{a b}}{\partial k_{2}}$ and $\frac{\partial a_{2}^{*}}{\partial k_{2}}$ has the sign of $\frac{\partial m_{a b}}{\partial k_{2}}$.

To prove Theorem 3, note from (9) that $\frac{\partial V_{F 2}}{\partial s_{2}}=\frac{\partial U_{F}}{\partial a_{2}} \frac{\partial a_{2}^{*}}{\partial s_{2}}+\frac{\partial U_{F}}{\partial b_{2}} \frac{\partial b_{2}^{*}}{\partial s_{2}}+\frac{\partial U_{F}}{\partial Y_{F 2}}$. Because $\frac{\partial U_{F}}{\partial a_{2}}=\frac{\partial U_{F}}{\partial b_{2}}$ at an interior solution, $\frac{\partial V_{F 2}}{\partial s_{2}}=\frac{\partial U_{F}}{\partial a_{2}}\left(\frac{\partial a_{2}^{*}}{\partial s_{2}}+\frac{\partial b_{2}^{*}}{\partial s_{2}}\right)+$ $\frac{\partial U_{F}}{\partial Y_{F 2}}$. But $a_{2}^{*}+b_{2}^{*}=1-e_{2}$ implies that $\frac{\partial a_{2}^{*}}{\partial s_{2}}+\frac{\partial b_{2}^{*}}{\partial s_{2}}=0$, so $\frac{\partial V_{F 2}}{\partial s_{2}}=$ $\frac{\partial U_{F}}{\partial Y_{F 2}}>0$. Similarly, because $\frac{\partial U_{F}}{\partial a_{2}}=\frac{\partial U_{F}}{\partial b_{2}}$ and $\frac{\partial a_{2}^{*}}{\partial x}+\frac{\partial b_{2}^{*}}{\partial x}=0$ for $x=$ $\phi, p_{2}, k_{2}, \frac{\partial V_{F 2}}{\partial \phi}=\frac{\partial U_{F}}{\partial a_{2}}\left(\frac{\partial a_{2}^{*}}{\partial \phi}+\frac{\partial b_{2}^{*}}{\partial \phi}\right)+\frac{\partial U_{F}}{\partial Y_{F 1}} \frac{\partial V_{F 2}}{\partial \phi}=\frac{\partial U_{F}}{\partial Y_{F 1}} L\left(p_{2}\right)>0$ and $\frac{\partial V_{F 2}}{\partial x}=$ 
$\frac{\partial U_{F}}{\partial a_{2}}\left(\frac{\partial a_{2}^{*}}{\partial x}+\frac{\partial b_{2}^{*}}{\partial x}\right)+\frac{\partial U_{F}}{\partial x}=\frac{\partial U_{F}}{\partial x}>0$ for $x=p_{2}, k_{2}$. Finally, because $\frac{\partial U_{F}}{\partial a_{2}}=$ $\frac{\partial U_{F}}{\partial b_{2}}$ and $\frac{\partial a_{2}^{*}}{\partial e_{2}}+\frac{\partial b_{2}^{*}}{\partial e_{2}}=-1, \frac{\partial V_{F_{2}}}{\partial e_{2}}=\frac{\partial U_{F}}{\partial a_{2}} \frac{\partial a_{2}^{*}}{\partial e_{2}}+\frac{\partial U_{F}}{\partial b_{2}} \frac{\partial b_{2}^{*}}{\partial e_{2}}=\frac{\partial U_{F}}{\partial a_{2}}\left(\frac{\partial a_{2}^{*}}{\partial e_{2}}+\frac{\partial b_{2}^{*}}{\partial e_{2}}\right)=$ $-\frac{\partial U_{F}}{\partial a_{2}}<0$. The results for indifference curves follow from the fact that $\frac{\partial I_{F 2}\left(e ; \phi, p_{2}, k_{2}, v\right)}{\partial x}=-\frac{\frac{\partial V_{F 2}}{\partial x}}{\frac{\partial V_{F}}{\partial s_{2}}}$ for $x=e_{2}, \phi, p_{2}, k_{2}$.

If there exists a $s_{L 2}>0$ such that $V_{F 2}\left(0, s_{L 2} ; \phi, p_{2}, k_{2}\right)=\bar{U}_{F 2}\left(\phi, p_{2}, k_{2}\right)$, then because $\frac{\partial V_{F 2}}{\partial s_{2}}>0>\frac{\partial V_{F 2}}{\partial e_{2}}$ by Theorem 3 , there exists a unique $s_{H 2}>$ $s_{L 2}$ such that $V_{F 2}\left(1, s_{H 2} ; \phi, p_{2}, k_{2}\right)=\bar{U}_{F}\left(\phi, p_{2}, k_{2}\right)$. It then follows from the implicit function theorem that there exists an $s_{2}=S_{2}\left(e_{2} ; \phi, p_{2}, k_{2}\right)$ such that $V_{F 2}\left(S_{2}\left(e_{2} ; \phi, p_{2}, k_{2}\right), e_{2} ; \phi, p_{2}, k_{2}\right)=\bar{U}_{F 2}\left(\phi, p_{2}, k_{2}\right)$ where, for given $\left(\phi, p_{2}, k_{2}\right), S_{2}$ maps $[0,1]$ onto $\left[s_{L 2}, s_{H 2}\right]$ and is increasing in $e_{2}$. Standard comparative statics show that $\frac{\partial S_{2}}{\partial e_{2}}=-\frac{\frac{\partial V_{F 2}}{\partial F_{2}}}{\frac{\partial V_{F 2}}{\partial s_{2}}}=\frac{\frac{\partial U_{F}}{\partial a}}{\frac{\partial U_{F}}{\partial Y_{F 2}}}>0, \frac{\partial S_{2}}{\partial \phi}=$ $-\frac{\frac{\partial V_{F 2}}{\partial \phi}-\frac{\partial \bar{U}_{F 2}}{\partial \phi}}{\frac{\partial V_{F 2}}{\partial s_{2}}}, \frac{\partial S_{2}}{\partial k_{2}}=-\frac{\frac{\partial V_{F 2}}{\partial k_{2}}-\frac{\partial \bar{U}_{F 2}}{\partial k_{2}}}{\frac{\partial V_{F 2}}{\partial s_{t}}}$, and $\frac{\partial S_{2}}{\partial p_{2}}=-\frac{\frac{\partial V_{F 2}}{\partial p_{2}}-\frac{\partial \bar{U}_{F 2}}{\partial p_{2}}}{\frac{\partial V_{F}}{\partial s_{2}}}$, which proves Theorem 4.

\subsection{Proofs of Theorems 5 and 6}

To prove Theorem 5, note from (13) that $\frac{\partial V_{A 2}}{\partial s_{2}}=\frac{\partial U_{A 2}}{\partial Y_{A 2}} \frac{\partial Y_{A 2}}{\partial s_{2}}=\frac{\partial U_{A 2}}{\partial Y_{A 2}}(-1)<0$, $\frac{\partial V_{A 2}}{\partial e_{2}}=\frac{\partial U_{A 2}}{\partial Y_{A 2}} \frac{\partial Y_{A 2}}{\partial e_{2}}=\frac{\partial U_{A 2}}{\partial Y_{A 2}} T^{\prime} \frac{\partial q_{2}}{\partial e_{2}}>0, \frac{\partial V_{A}}{\partial \phi}=\frac{\partial U_{A 2}}{\partial Y_{A 2}} \frac{\partial Y_{A 2}}{\partial \phi}=\frac{\partial U_{A 2}}{\partial Y_{A 2}}(-L)<0$, $\frac{\partial V_{A 2}}{\partial p_{2}}=\frac{\partial U_{A 2}}{\partial Y_{A 2}} \frac{\partial Y_{A 2}}{\partial p_{2}}+\frac{\partial U_{A 2}}{\partial p_{2}}=\frac{\partial U_{A 2}}{\partial Y_{A 2}}\left(T^{\prime} \frac{\partial q_{2}}{\partial\left(\theta p_{2}\right)} \theta+(1-\phi) L^{\prime}\right)+\frac{\partial U_{A 2}}{\partial p_{2}}>0, \frac{\partial V_{A 2}}{\partial k_{2}}=$ $\frac{\partial U_{A 2}}{\partial Y_{A 2}} \frac{\partial Y_{A 2}}{\partial k_{2}}+\frac{\partial U_{A 2}}{\partial k_{2}}=\frac{\partial U_{A 2}}{\partial Y_{A 2}} T^{\prime} \frac{\partial q_{2}}{\partial k_{2}}+\frac{\partial U_{A 2}}{\partial k_{2}}>0$, and $\frac{\partial V_{A 2}}{\partial \theta}=\frac{\partial U_{A 2}}{\partial Y_{A} 2} T^{\prime} \frac{\partial q_{2}}{\partial\left(\theta p_{2}\right)} p_{2}>0$.

One can show $\frac{\partial I_{F 2}}{\partial e_{2}}=-\frac{\frac{\partial V_{F 2}}{\partial e_{2}}}{\frac{\partial V_{F 2}}{\partial s_{2}}}=\frac{\frac{\partial U_{F}}{\partial a}}{\frac{\partial U_{F}}{\partial Y_{F 2}}}>0$, and $\frac{\partial I_{A 2}}{\partial e_{2}}=-\frac{\frac{\partial V_{A 2}}{\partial e_{2}}}{\frac{\partial V_{A 2}}{\partial s_{2}}}=T^{\prime} \frac{\partial q_{2}}{\partial e_{2}}>$ 0 , while $\frac{\partial^{2} I_{F 2}}{\partial e_{2}^{2}}=\left(\frac{\partial V_{F 2}}{\partial s_{2}}\right)^{-3}\left(2 \frac{\partial^{2} V_{F 2}}{\partial e_{2} \partial s_{2}} \frac{\partial V_{F 2}}{\partial s_{2}} \frac{\partial V_{F 2}}{\partial e}-\frac{\partial^{2} V_{F 2}}{\partial e_{2}^{2}}\left(\frac{\partial V_{F 2}}{\partial s_{2}}\right)^{2}-\frac{\partial^{2} V_{F 2}}{\partial s_{2}^{2}}\left(\frac{\partial V_{F 2}}{\partial e_{2}}\right)\right)^{2}$ and $\frac{\partial^{2} I_{A 2}}{\partial e_{2}^{2}}=\left(\frac{\partial V_{A 2}}{\partial s_{2}}\right)^{-3}\left(2 \frac{\partial^{2} V_{A 2}}{\partial e_{2} \partial s_{2}} \frac{\partial V_{A 2}}{\partial s_{2}} \frac{\partial V_{A 2}}{\partial e_{2}}-\frac{\partial^{2} V_{A 2}}{\partial e_{2}^{2}}\left(\frac{\partial V_{A 2}}{\partial s_{2}}\right)^{2}-\frac{\partial^{2} V_{A 2}}{\partial s_{2}^{2}}\left(\frac{\partial V_{A 2}}{\partial e_{2}}\right)^{2}\right)$. Hence, given any $I_{F}$, such as the one associated with the participation constraint, the problem of choosing an $\left(e_{2}^{*}, s_{2}^{*}\right)$ on that $I_{F 2}$ to maximize $V_{A 2}$ is equivalent to choosing the $\left(e_{2}^{*}, s_{2}^{*}\right)$ on that $I_{F 2}$ associated with the "highest" (most southeast) $I_{A 2}$. Thus, because the researcher's indifference curves are increasing and strictly convex, while the administration's indifference curves are increasing and strictly concave, this is given by the tangency of an $I_{A 2}$ with this $I_{F 2}$. The conditions $\frac{\partial I_{A 2}\left(0 ; \phi, \theta, p_{2}, k_{2}, v\right)}{\partial e_{2}}>\frac{\partial I_{F 2}\left(0 ; \phi, p_{2}, k_{2}, v\right)}{\partial e_{2}}$, and $\frac{\partial I_{A 2}\left(1 ; \phi, \theta, p_{2}, k_{2}, v\right)}{\partial e_{2}}<\frac{\partial I_{F 2}\left(1 ; \phi, p_{2}, k_{2}, v\right)}{\partial e_{2}}$ for all $\left(\phi, \theta, p_{2}, k_{2}, v\right)$ guarantee that 
this tangency must be at an $e_{2}^{*} \in[0,1]$. That the solution also satisfies $s_{2}^{*} \in\left[s_{20}, s_{21}\right]$ then follows from Theorem 4 .

\subsection{Proofs of Theorem 9, 10, and 11}

If $N_{F 1}\left(b_{1} ; s_{1}, \phi, p_{1}, k_{1}\right)=W_{F}\left(1-e_{1}-b_{1}, b_{1} ; s_{1}, \phi, p_{1}, k_{1}\right)$, then the proof of Theorem 9 is entirely analogous to that of Theorem 1 , with $N_{F 1}$ replacing $N_{F 2}, W_{F}$ replacing $U_{F}$, and $t=1$ replacing $t=2$. Similarly, the comparative statics results in Theorem 10 are proved in the same way as those in Theorem 2 with the addition that $M_{a b}$ replaces $m_{a b}$.

To prove the first part of Theorem 11, as in the proof of Theorem 3, use $\frac{\partial W_{F}}{\partial a_{1}}=\frac{\partial W_{F}}{\partial b_{1}}$ and $\frac{\partial a_{1}^{*}}{\partial x}+\frac{\partial b_{1}^{*}}{\partial x}=0$ for $x=s_{1}, \phi, p_{1}, k_{1}$ at an interior solution to show that $\frac{\partial V_{F 1}}{\partial x}=\frac{\partial W_{F}}{\partial x}$ for these $x$. And because $\frac{\partial a_{1}^{*}}{\partial e_{1}}+\frac{\partial b_{1}^{*}}{\partial e_{1}}=-1, \frac{\partial W_{F}}{\partial e_{1}}=$ $\frac{\partial W_{F}}{\partial a_{1}} \frac{\partial a_{1}^{*}}{\partial e_{1}}+\frac{\partial W_{F}}{\partial b_{1}} \frac{\partial b_{1}^{*}}{\partial e_{1}}=\frac{\partial W_{F}}{\partial a_{1}}\left(\frac{\partial a_{1}^{*}}{\partial e_{1}}+\frac{\partial b_{1}^{*}}{\partial e_{1}}\right)=-\frac{\partial W_{F}}{\partial a_{1}}$. The results for indirect utility follow from the assumptions on the composite marginal utilities, and those for the indifference curves then follow from these assumptions and the fact that $\frac{\partial I_{F 1}\left(e_{1} ; \phi, p_{1}, k_{1}, v\right)}{\partial x}=-\frac{\frac{\partial W_{F}}{\partial x}}{\frac{\partial W_{F}}{\partial s_{1}}}$ for $x=e_{1}, \phi, p_{1}, k_{1}$.

If there exists a $s_{L 1}>0$ such that $V_{F 1}\left(0, s_{L 1} ; \phi, p_{1}, k_{1}\right)=\bar{U}_{F 1}\left(\phi, p_{1}, k_{1}, \delta\right)$, then because $\frac{\partial V_{F 1}}{\partial s_{1}}>0>\frac{\partial V_{F 1}}{\partial e_{1}}$ from above, there exists a unique $s_{H 1}>s_{L 1}$ such that $V_{F 1}\left(1, s_{H 1} ; \phi, p_{1}, k_{1}\right)=\bar{U}_{F 1}\left(\phi, p_{1}, k_{1}, \delta\right)$. It then follows from the implicit function theorem that there exists an $s=S_{1}\left(e_{1} ; \phi, p_{1}, k_{1}\right)$ such that $V_{F 1}\left(e_{1}, S_{1}\left(e_{1} ; \phi, p_{1}, k_{1}\right) ; \phi, p_{1}, k_{1}\right)=\bar{U}_{F 1}\left(\phi, p_{1}, k_{1}, \delta\right)$ where, for given $\left(\phi, p_{1}, k_{1}, \delta\right), S_{1}$ maps $[0,1]$ onto $\left[s_{L 1}, s_{H 1}\right]$ and is increasing in $e_{1}$. Standard comparative statics show that $\frac{\partial S_{1}}{\partial e_{1}}=-\frac{\frac{\partial V_{F 1}}{\partial e_{1}}}{\frac{\partial V_{F 1}}{\partial s_{1}}}>0, \frac{\partial S_{1}}{\partial \phi}=-\frac{\left(\frac{\partial V_{F 1}}{\partial \phi}-\frac{\partial \bar{U}_{F 1}}{\partial \phi}\right)}{\frac{\partial V_{F 1}}{\partial s_{1}}}$, $\frac{\partial S_{1}}{\partial k_{1}}=-\frac{\left(\frac{\partial V_{F 1}}{\partial k_{1}}-\frac{\partial \bar{U}_{F 1}}{\partial k_{1}}\right)}{\frac{\partial V_{F 1}}{\partial s_{1}}}$, and $\frac{\partial S_{1}}{\partial p_{1}}=-\frac{\left(\frac{\partial V_{F 1}}{\partial p_{1}}-\frac{\partial \bar{U}_{F 1}}{\partial p_{1}}\right)}{\frac{\partial V_{F 1}}{\partial s_{1}}}$, which proves statements (i) and (ii) of Theorem 11.

\subsection{Proofs of Theorems 12 and 13}

From (30), for $x=e_{1}, s_{1}, \phi, \theta, p_{1}, k_{1}, \frac{\partial W_{A}}{\partial x}=\frac{\partial V_{A 1}}{\partial x}+\delta \frac{\partial V_{A 2}^{*}}{\partial x}=\frac{\partial V_{A 1}}{\partial x}+\delta\left(\frac{\partial V_{A 2}}{\partial e_{2}} \frac{\partial e_{2}^{*}}{\partial p_{2}}+\right.$ $\left.\frac{\partial V_{A 2}}{\partial s_{2}} \frac{\partial s_{2}^{*}}{\partial p_{2}}+\frac{\partial V_{A 2}}{\partial p_{2}}\right)\left(\frac{\partial P}{\partial a_{1}} \frac{\partial a_{1}^{*}}{\partial x}+\frac{\partial P}{\partial b_{1}} \frac{\partial b_{1}^{*}}{\partial x}\right)+\delta\left(\frac{\partial V_{A 2}}{\partial e_{2}} \frac{\partial e_{2}^{*}}{\partial k_{2}}+\frac{\partial V_{A 2}}{\partial s_{2}} \frac{\partial s_{2}^{*}}{\partial k_{2}}+\frac{\partial V_{A 2}}{\partial k_{2}}\right)\left(\frac{\partial K}{\partial a_{1}} \frac{\partial a_{1}^{*}}{\partial x}+\right.$ $\left.\frac{\partial K}{\partial b_{1}} \frac{\partial b_{1}^{*}}{\partial x}\right)$, which is generally ambiguous. For $x=s_{1}, \phi, p_{1}, k_{1}$, note that $\frac{\partial a_{1}^{*}}{\partial x}+\frac{\partial b_{1}^{*}}{\partial x}=0$ implies $\frac{\partial W_{A}}{\partial x}=\frac{\partial V_{A 1}}{\partial x}+\delta\left(\frac{\partial V_{A 2}}{\partial e_{2}} \frac{\partial e_{2}^{*}}{\partial p_{2}}+\frac{\partial V_{A 2}}{\partial s_{2}} \frac{\partial s_{2}^{*}}{\partial p_{2}}+\frac{\partial V_{A 2}}{\partial p_{2}}\right)\left(\frac{\partial P}{\partial a_{1}}-\frac{\partial P}{\partial b_{1}}\right) \frac{\partial b_{1}^{*}}{\partial x}$ $+\delta\left(\frac{\partial V_{A 2}}{\partial e_{2}} \frac{\partial e_{2}^{*}}{\partial k_{2}}+\frac{\partial V_{A 2}}{\partial s_{2}} \frac{\partial s_{2}^{*}}{\partial k_{2}}+\frac{\partial V_{A 2}}{\partial k_{2}}\right)\left(\frac{\partial K}{\partial a_{1}}-\frac{\partial K}{\partial b_{1}}\right) \frac{\partial b_{1}^{*}}{\partial x}$. However, because $\frac{\partial a_{1}^{*}}{\partial \theta}=\frac{\partial b_{1}^{*}}{\partial \theta}=$ $0, \frac{\partial W_{A}}{\partial \theta}=\frac{\partial V_{A 1}}{\partial \theta}=\frac{\partial U_{A}}{\partial Y_{A 1}} \frac{\partial Y_{A 1}}{\partial q_{1}} \frac{\partial q_{1}}{\partial \theta}>0$. 
To solve (32), form the Lagrangian $£\left(e_{1}, s_{1}, \lambda\right)=W_{A}\left(e_{1}, s_{1} ; \phi, \theta, p_{1}, k_{1}\right)+$ $\lambda\left[W_{F}\left(e_{1}, s_{1}, \phi, p_{1}, k_{1}\right)-\bar{U}_{F 1}\left(\phi, p_{1}, k_{1}, \delta\right)\right]$. Using ordinary techniques, the first order conditions for an interior solution can be written as $\lambda=-\frac{\frac{\partial W_{A}}{\partial e_{1}}}{\frac{\partial W_{F}}{\partial e_{1}}}=$ $-\frac{\frac{\partial W_{A}}{\partial s_{1}}}{\frac{\partial W_{F}}{\partial F_{1}}}$ and $W_{F}\left(e_{1}, s_{1}, \phi, p_{1}, k_{1}\right)=\bar{U}_{F 1}\left(\phi, p_{1}, k_{1}, \delta\right)$. The former implies $\frac{\partial I_{A 1}}{\partial e_{1}}=$ $\frac{\partial I_{F 1}}{\partial e_{1}}$, which with the participation constraint proves (33). Again using standard techniques, the second order sufficient condition for a constrained maximum is $2 \frac{\partial^{2} W_{A}}{\partial e_{1} \partial s_{1}} \frac{\partial W_{F}}{\partial w} \frac{\partial W_{F}}{\partial s_{1}}-\frac{\partial^{2} W_{A}}{\partial e_{1}^{2}}\left(\frac{\partial W_{F}}{\partial s_{1}}\right)^{2}-\frac{\partial^{2} W_{A}}{\partial s_{1}^{2}}\left(\frac{\partial W_{F}}{\partial e_{1}}\right)^{2}+2 \lambda \frac{\partial^{2} W_{F}}{\partial e_{1} \partial s_{1}} \frac{\partial W_{F}}{\partial e_{1}} \frac{\partial W_{F}}{\partial s_{1}}-$ $\lambda \frac{\partial^{2} W_{F}}{\partial e_{1}^{2}}\left(\frac{\partial W_{F}}{\partial s_{1}}\right)^{2}-\lambda \frac{\partial^{2} W_{F}}{\partial s_{1}^{2}}\left(\frac{\partial W_{F}}{\partial e_{1}}\right)^{2} \geq 0$. Substituting for $\lambda$ from the first order conditions, using the participation constraint, and rearranging terms, this can be rewritten as $\lambda^{-2}\left(\frac{\partial W_{A}}{\partial s_{1}}\right)^{3}\left[\frac{\partial^{2} I_{A}}{\partial e_{1}^{2}}-\frac{\partial^{2} S_{1}}{\partial e_{1}^{2}}\right] \geq 0$. Because $\frac{\partial W_{A}}{\partial s_{1}}<0$, this is equivalent to $\frac{\partial^{2} I_{A}}{\partial e_{1}^{2}} \leq \frac{\partial^{2} S}{\partial e_{1}^{2}}$. Thus, because the researcher's indifference curves are increasing and strictly convex, this condition merely requires the administration's (increasing) indifference curves to be less convex, or even concave. The conditions $\frac{\partial I_{A 1}\left(0 ; \phi, \theta, p_{1}, k_{1}, v\right)}{\partial e_{1}}>\frac{\partial S_{1}\left(0 ; \phi, p_{1}, k_{1}, \delta\right)}{\partial e_{1}}$ and $\frac{\partial I_{A 1}\left(1 ; \phi, \theta, p_{1}, k_{1}, v\right)}{\partial e_{1}}<\frac{\partial S_{1}\left(1 ; \phi, p_{1}, k_{1}, \delta\right)}{\partial e_{1}}$ for all $\left(\phi, \theta, p_{1}, k_{1}, \delta, v\right)$ guarantee that this tangency must be at an $e_{1}^{*} \in(0,1)$. That the solution also satisfies $s_{1}^{*}=$ $S_{1}\left(e_{1}^{*}, \phi, p_{1}, k_{1}, \delta\right) \in\left(s_{L 1}, s_{H 1}\right)$ then follows from Theorem 11. 


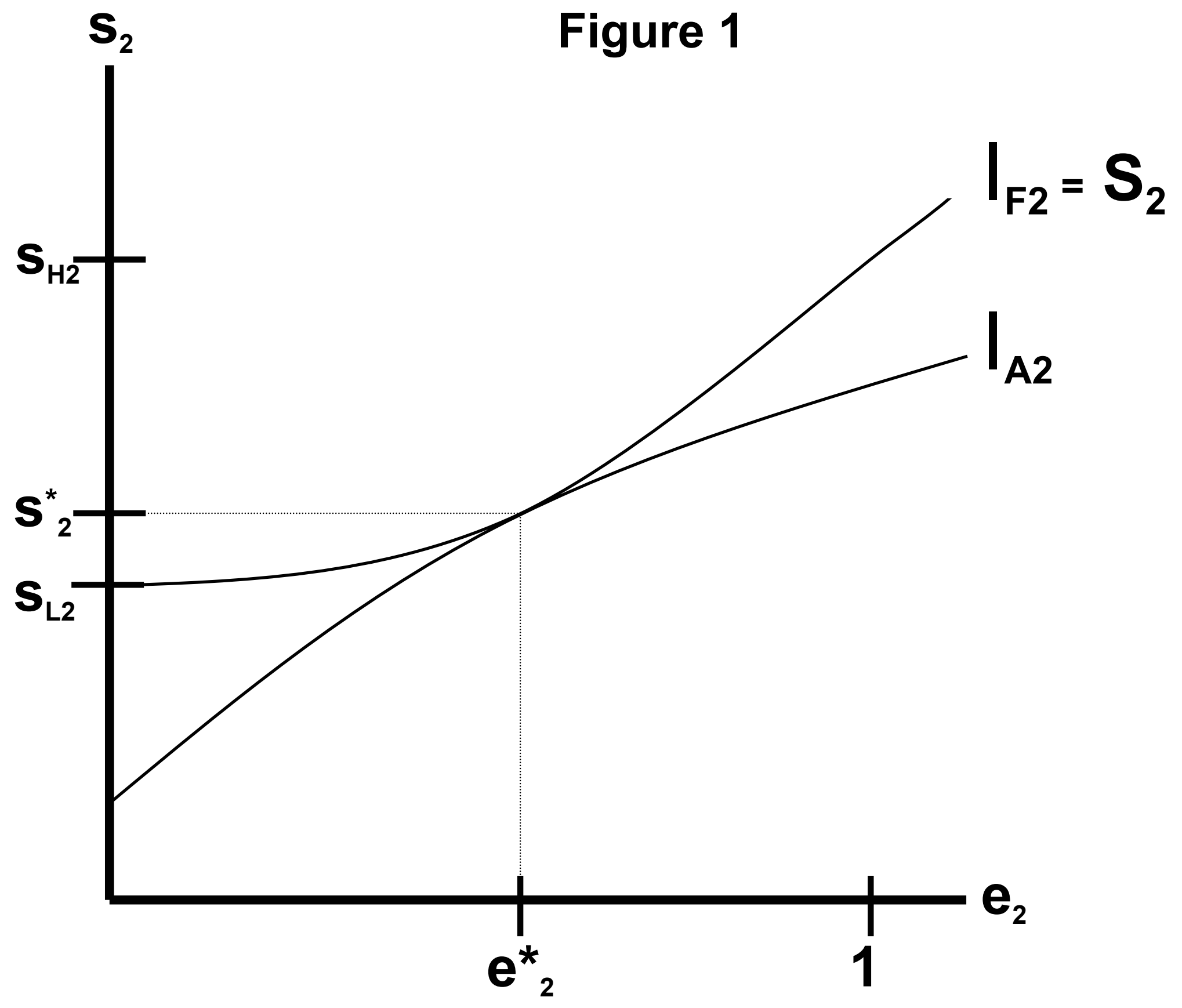

